\title{
LA RESTRICCIÓN DE LOS DERECHOS FUNDAMENTALES: UN CONCEPTO EN EVOLUCIÓN Y SU FUNDAMENTO CONSTITUCIONAL
}

\author{
MARÍA JOSÉ CABEZUDO BAJO
}




\section{SUMARIO}

I. CONCEPTO. 1. La problemática de su exposición. A) La formulación de la noción en España y la incorporación de su equivalente en el ordenamiento jurídico alemán. B) La evolución de la "Grundrechtseingriff" y su repercusión en España. a) Las nuevas formas de violación derivadas del incumplimiento del deber de protección estatal. a') Causa del deber: la vertiente objetiva de los Derechos Fundamentales. b') Los nuevos supuestos de violación. a“) Entre el Estado y los particulares: violaciones involuntarias y fácticas y las omisiones del Poder Ejecutivo. b“) Entre particulares no vinculados jurídicamente. c") Entre particulares sometidos a una relación jurídico-privada. b) La crisis del concepto clásico de "Grundrechtseingriff». 2. La nueva concepción de la "restricción de los Derechos Fundamentales». A) Concepto. B) Requisitos. II. FUNDAMENTO CONSTITUCIONAL. 1. La teoría de la «doble estructura de la Norma de Derecho Fundamental» de Alexy y la jurisprudencia del TC. 2. La implícita proclamación en cada una de las «Normas de Derecho Fundamental». III. CONCLUSIONES 


\title{
LA RESTRICCIÓN DE LOS DERECHOS FUNDAMENTALES: UN CONCEPTO EN EVOLUCIÓN Y SU FUNDAMENTO CONSTITUCIONAL ${ }^{1}$
}

\author{
POR \\ MARÍA JOSÉ CABEZUDO BAJO \\ Departamento de Derecho Procesal (UNED) \\ mcabezudo@der.uned.es
}

El concepto de «restricción de los Derechos Fundamentales» presenta una extraordinaria utilidad para el campo del Derecho Procesal. Esta circunstancia se pone de relieve a la hora de precisar las exigencias constitucionales que han de cumplir aquellos actos procesales que inciden sobre derechos fundamentales para alcanzar la eficacia procesal que persiguen. Es el caso, por ejemplo, de la entrada y registro domiciliario, la intervención de las comunicaciones telefónicas o las novedosas medidas relativas a la intervención y acceso de los datos de tráfico de las comunicaciones electrónicas, así como a la obtención y tratamiento del $\mathrm{ADN}$ e, incluso, de las medidas que cabe adoptar para luchar contra la criminalidad organizada, como la infiltración de un agente encubierto o la instalación de aparatos de escucha sobre un domicilio, cuya adopción, todos ellos, por

${ }^{1}$ Este trabajo ha sido realizado parcialmente en el marco del Proyecto de Investigación concedido por el Ministerio de Ciencia e Innovación, cuya referencia es DER 2009-08071. Asimismo, quiero manifestar mi profundo agradecimiento al prof. Antonio Torres del Moral por las valiosas sugerencias que ha formulado a este trabajo. 
parte del órgano jurisdiccional competente, esta orientada a la consecución de los fines propios del proceso penal, civil, así como del procedimiento administrativo. Por el hecho de incidir sobre derechos fundamentales, dichas actuaciones procesales deberían constituir restricciones o limitaciones de tales derechos, lo que significa que su eficacia procesal ha de estar sometida al más estricto cumplimiento de las exigencias constitucionales que dicha calificación conlleva. Por ello, ha de formularse el concepto de «restricción de los Derechos Fundamentales», con el objeto de precisar los presupuestos y requisitos que lo conforman. Este es precisamente el objeto de este trabajo, la exposición, en la medida en que resulta necesaria desde esta perspectiva procesal, del concepto, en evolución, de «restricción de los Derechos Fundamentales», así como su fundamento constitucional.

\section{CONCEPTO}

Con el fin de alcanzar la eficaz salvaguarda de los derechos fundamentales frente a las vulneraciones ocasionadas por los poderes públicos, nuestra Constitución ha previsto diferentes instrumentos jurídicos. Dichos mecanismos, que inicialmente se han utilizado para la defensa de tales derechos frente a las actuaciones vulneradoras del Estado, han tenido que ir adecuándose asimismo a las violaciones ocasionadas ante la omisión, por parte de tales autoridades, del deber de garantizarlos. Uno de estos instrumentos, el relativo a la «restricción de los Derechos Fundamentales», que, desde un punto de vista procesal se utiliza fundamentalmente frente a las actuaciones vulneradoras del Estado, se ha visto influido igualmente por esta evolución. La utilidad que presenta la formulación del concepto de «restricción de Derechos Fundamentales», comprensivo de ambos supuestos, esto es, de las violaciones de los Derechos Fundamentales ocasionadas, tanto por una «acción» como por una «omisión» de los poderes públicos, justifica que se inicie este trabajo con su exposición. Ello no obstante, con carácter previo, ha de incidirse en el hecho de que el desarrollo de su contenido no se encuentra asimismo exento de dificultades.

\section{La problemática de su exposición}

La denominación de aquellas actuaciones de los poderes públicos que inciden sobre los derechos fundamentales, como restricciones o limitaciones de estos derechos, no plantea objeción alguna, pues así han sido calificadas funda- 
mentalmente por nuestro Tribunal Constitucional ${ }^{2}$. Admitido lo anterior, cabe plantearse dos cuestiones.

La primera interrogante parte del hecho de que tal noción no ha sido suficientemente sistematizada por nuestra doctrina, aun cuando de la jurisprudencia de nuestro Tribunal Constitucional se infieren algunos de sus elementos. Sin embargo, resulta esencial precisar, con carácter general, el contenido de dicha expresión jurídica, distinguiendo sus presupuestos y requisitos ${ }^{3}$. De esta manera, si dichos presupuestos y requisitos fueran aplicados, en cada caso, por el legislador y los órganos jurisdiccionales, sobre aquellos actos procesales que inciden sobre derechos fundamentales, se contribuiría a su eficacia procesal. Para resolver esta primera pregunta, resulta extraordinariamente útil la toma en consideración del concepto alemán equivalente, "Grundrechtseingriff». Dicha noción ha sido configurada por la doctrina alemana y, en virtud de la jurisprudencia del Tribunal Constitucional Federal Alemán (en adelante, BVerfG) y del Tribunal Federal Administrativo (en adelante, BVerwG), se ha ido completando su contenido.

La segunda incógnita toma como punto de partida la circunstancia de que a la vertiente clásica de dicho concepto, esto es, la que permite proteger los derechos fundamentales frente a las actuaciones vulneradoras de los poderes públicos, debieran irse incorporando aquellas peculiaridades derivadas del reconocimiento, también como violaciones de los derechos fundamentales, de aquellas vulneraciones ocasionadas ante la omisión de los poderes públicos de su deber de garantizarlos. La exposición de esta nueva vertiente de la noción objeto de estudio es fundamental si se pretende que dicho instrumento jurídico, en que consiste la «restricción de los derechos Fundamentales», resulte igualmente eficaz

2 Esta calificación es la utilizada por el TC, entre otras, en las SSTC 62/1982, de 15 de octubre (FJ $2^{\circ}$ ); 27/1989, de 3 de febrero (FJ $1^{\circ}, 2^{\circ}$ y $\left.4^{\circ}\right) ; 137 / 1990$, de 19 de julio (FJ $10^{\circ}$ ); 66/1995, de 8 de mayo (FJ 3 $3^{\circ}$; 62/1996, de 15 de abril (FJ 4º); 170/1996, de 29 de octubre (FJ $\left.4^{\circ}\right)$; 207/1996, de 16 de (FJ $4^{\circ}$ ); 67/1997, de 7 de abril (FJ2 ${ }^{\circ}$ ); 123/1997, de 1 de julio (FJ $3^{\circ}$ y $\left.4^{\circ}\right) ; 128 / 1997$, de 14 de julio (FJ 4º); 146/1997, de 15 de septiembre (FJ 5०); 156/1997, de 29 de septiembre $\left(\mathrm{FJ} \mathrm{4} 4^{\circ}\right) ; 157 / 1997$, de 29 de septiembre ( FJ $4^{\circ}$ y $5^{\circ}$ ); 200/1997, de 24 de noviembre $\left(\mathrm{FJ} 4^{\circ}\right) ; 201 / 1997$, de 25 de noviembre $\left(\mathrm{FJ} 7^{\circ}\right) ; 58 / 1998$, de 16 de marzo (FJ $\left.3^{\circ}\right) ; 112 / 2000$, de 5 de mayo (FJ 6 ${ }^{\circ}$ ); 126/2000, de 16 de mayo (FJ 6 ${ }^{\circ}$ ); 127/2000, de 16 de mayo (FJ 3º); 297/2000, de 11 de diciembre $\left(\mathrm{FJ} \mathrm{3}^{\circ}\right)$; 282/2000, de 27 de noviembre (FJ $\left.2^{\circ}\right) ; 292 / 2000$, de 30 de noviembre (FJ $15^{\circ}$ y $\left.16^{\circ}\right) ; 102 / 2001$, de 23 de abril (FJ 3 ${ }^{\circ}$ ); 8/2002, de 14 de enero (FJ 3); 207/2007, de 24 de septiembre $\left(\mathrm{FJ} 5^{\circ}\right)$.

3 La institución relativa a la «restricción de los Derechos Fundamentales» es objeto de un primer análisis en CABEZUDO BAJO, «La inviolabilidad del domicilio y el proceso penal», Madrid, 2004, pp. 27-31. Se avanzó, profundizando en relación con su naturaleza jurídica, presupuestos y requisitos en CABEZUDO BAJO, «La restricción de los derechos fundamentales», RDP, $\mathrm{n}^{\circ}$ 62, 2005, pp. 194- 227.

(C) UNED. Revista de Derecho Político 
frente a estas nuevas formas de violación de tales derechos. Una medida que cabe adoptar para desarrollar esta cuestión consiste en tomar en cuenta la evolución que el propio concepto ha sufrido en la doctrina alemana y jurisprudencia del $\mathrm{BVerfG}$, puesto que, en nuestro sistema constitucional, los derechos fundamentales han sufrido un desarrollo semejante.

A) La formulación de la noción en España y la incorporación de su equivalente en el ordenamiento jurídico alemán

Aun cuando el concepto de «restricción de los Derechos Fundamentales» no se ha desarrollado profusamente en España, de la citada jurisprudencia de nuestro Tribunal Constitucional hemos derivado la idea básica del concepto. Dicho punto esencial consiste en afirmar que, si bien las actuaciones de los poderes públicos que inciden sobre derechos fundamentales pudieran resultar en principio lesivas de tales derechos, lo cierto es que si efectivamente están justificadas en el principio de proporcionalidad, constituirán medidas constitucionalmente legítimas.

Se infiere tal afirmación si se parte, como así hace la doctrina ${ }^{4}$ y el Tribunal Constitucional ${ }^{5}$, de que ni los derechos fundamentales son absolutos, ni tampoco sus límites; y, ello sin perjuicio de que, a la primera expresión, cabrían oponerse algunas excepciones, como, por ejemplo, el derecho a la integridad física y psíquica (art. $15 \mathrm{CE}$ ). Por el contrario, derechos y límites se sitúan en un régimen de "concurrencia normativa» cuya expresión equivalente en el Derecho alemán es la «teoría de la interacción» ("Wechselwirkungs Theorie»), en el sentido de que actúan recíprocamente, tal y como se deriva del artículo 10.1 de la Consti-

${ }^{4}$ GUAITA, «Régimen de los derechos constitucionales», RDPo, n 13, 1982, p. 82; AGUIAR, «Dogmática y teoría jurídica de los Derechos Fundamentales en la interpretación de estos por el Tribunal Constitucional Español», RDPo, n 18/19, 1983, p. 28; PRIETO SANCHÍS, «Sobre el concepto jurídico de Derechos Fundamentales», Revista Jurídica de Castilla La Mancha, nº 8-9, dic-abril 1989-1990, pp. 244 y 245; el mismo autor en «La limitación de los derechos fundamentales y la norma de clausura del sistema de libertades». Derechos y libertades. Revista del Instituto Bartolomé de las Casas, enero/junio 2000, nº 8, p. 434; FERNÁNDEZ SEGADO, La dogmática de los derechos fundamentales, Perú, 1997, p. 101. TORRES DEL MORAL, Principios de Derecho Constitucional Español, Tomo I, Madrid, 5a ed., 2004, pp. 274 y 275.

${ }^{5}$ A modo de ejemplo, las SSTC 11/1981, de 8 de abril (FJ $7^{\circ}$ ); 2/1982, de 29 de enero (FJ $\left.5^{\circ}\right) ; 81 / 1983$, de 10 de octubre (FJ $2^{\circ}$ ); 105/1997, de 2 de junio $\left(\mathrm{FJ} 4^{\circ}\right.$ ).

${ }^{6}$ Dicha teoría se origina con el famoso caso Lüth, en la BVerfG 7, 198 (208 y ss), que resulta de aplicación general según el propio BverfG y ha sido asumida por la doctrina alemana y, en particular, por BÖCKENFÖRDE, Escritos sobre Derechos Fundamentales, Baden-Baden, 1993, p. 102. 
tución, según ha manifestado nuestro Tribunal Constitucional ${ }^{7}$ y un sector de la doctrina constitucionalista ${ }^{8}$. En el marco de esta relación y dada la posición privilegiada que los derechos fundamentales ocupan en nuestro ordenamiento", debe restringirse el alcance de las normas limitadoras que actúan sobre ellos, lo que significa que los límites deben interpretarse restrictivamente ${ }^{10} \mathrm{y}$ en el sentido más favorable a la eficacia y esencia de los dichos derechos.

De conformidad con esta noción que subyace tras la expresión restricción o limitación de los Derechos Fundamentales, debieran interpretarse otros términos consagrados constitucionalmente, que aluden asimismo a la idea de menoscabo, afectación o delimitación, tales como "privación" (de la libertad, en el art. 17.1 CE) y «exceptuar» (en relación con el derecho a sindicarse libremente, en el art. 28.1 CE), «limitación» (de la libertad ideológica, religiosa y de culto, en el art. 16; del derecho al honor, intimidad personal y familiar, en el art.18.4; del derecho a entrar y salir libremente de España, en el art. 19 II; y del derecho a sindicarse libremente, en el art. 28.1 CE) y «restricción» (de los derecho a expresar y difundir libremente pensamientos, ideas y opiniones, a la producción y creación literaria, artística, científica y técnica, a la libertad de cátedra y a comunicar o recibir libremente información veraz, en el art. 20.2 CE). E, incluso, se entiende que constituyen igualmente restricciones al domicilio inviolable, la entrada en dicho lugar y su registro, a través de una resolución judicial o flagrante delito (art. 18.2 CE) o la intervención de las comunicaciones secretas, mediante una resolución judicial (art. 18.3 CE), aun cuando la Constitución no utilice explícitamente ninguna de las expresiones jurídicas anteriormente indicadas.

En virtud de la correspondencia entre la mencionada conformidad constitucional y la expresión «restricción» o «limitación» de los derechos fundamentales, puede identificarse el concepto equivalente, "Grundrechtseingriff", utilizado por la jurisprudencia del BVerfG ${ }^{11}$ y elaborado por un amplio sector de la

7 Así, por ejemplo, SSTC 159/1986, de 12 de diciembre (FJ 6º); 254/1988, de 21 de diciembre $\left(\mathrm{FJ} 3^{\circ}\right)$.

8 FERNÁNDEZ SEGADO, «La teoría jurídica de los derechos fundamentales en la doctrina constitucional», REDC, n 39, sep-dic 1993, p. 236; el mismo autor, La dogmática de.., op. cit., p. 102.

9 Entre otras, SSTC 66/1985, de 23 de mayo (FJ 2); 6/1995, de 10 de enero (FJ 2º); 186/1996, de 25 de noviembre (FJ $3^{\circ}$ ).

${ }^{10}$ En este sentido, TORRES DEL MORAL, Principios de Derecho..., op. cit., p. 315.

11 En cuanto al BVerfG, cuando ha querido referirse a aquellas medidas vulneradoras ("beeinträchtigende Massnahme») del ámbito de libertad ha utilizado la expresión intromisión ("Eingriff»). Es el caso, por ejemplo, de las BVerfGE 52, 283 [296]; BVerfGE 57,9 [23]; BVerfGE 61, 291 [309,311], BVerfGE 65,1 [45]; BVerfGE 66, 39 [64]; BVerfGE 68, 193 [205], BVerfGE 69, 
doctrina germana ${ }^{12}$, entre los que destaca el formulado por Alexy. En este sentido, el citado autor ${ }^{13}$ ha manifestado, que con la realización de una intromisión ("Eingriff") en un ámbito constitucionalmente protegido ("Schutzbereich»), lo que conforma el supuesto de hecho del derecho fundamental ("Tatbestand») y en cuyo caso se activa el efecto protector de tal derecho, surge la necesidad de justificación ("Rechtfertigung»), por lo que se aplica la consecuencia jurídica ("Rechtsfolge»), que consiste en afirmar que la medida se encuentra prima facie iusfundamentalmente prohibida. Sólo en el caso de que tal medida se justifique por un límite ( SSchranken») está definitiva y iusfundamentalmente permitida. En tal caso, estamos ante una medida restrictiva de derechos fundamentales. Por el contrario, en caso de que la medida no se justifique, el derecho fundamental resulta definitivamente vulnerado ${ }^{14}$.

Si aplicamos esta formulación a un caso concreto, por ejemplo, a los actos procesales en que consisten la entrada y registro en un domicilio en el proceso penal, nos llevaría a afirmar lo siguiente: si llevamos a cabo una intromisión, bien una entrada o bien una entrada seguida de un registro (art. 18.2 CE), sobre el ámbito constitucionalmente protegido por dicha norma (art. 18.2 CE), esto es, en un lugar calificable como domicilio ex Constitutione, se cumple el supuesto

315 [342], cit. en ECKHOFF, Der Grundrechtseingriff..., op. cit., p. 5, si bien, en algunos otros supuestos, tales como BVerfGE 65, 1 [44,45]; BVerfGE 69, 315 [341], cit. en ECKHOFF, Der Grundrechtseingriff..., op. cit., p. 5, el Tribunal de Karlsrhue ha manifestado que constituyen además, y como conceptos sinónimos, «limitaciones» o "restricciones» denominadas "Einschränkungen».

${ }_{12}$ En este sentido, vide LERCHE, «Grundrechtlicher Schutzbereich, Grundrechtsprägung und Grundrechtseingriff», ISENSEE;KIRCHHOF, Handbuch des Staatsrechts, Band V, Heidelberg, 1992, pp. 739 y ss; ECKHOFF, Grundrechtseingriff, Köln, Berlín, Bonn, München, 1992, pp. 9 y 19; ALEXY, Teoría de los derechos fundamentales, Madrid, $1^{\circ}$ reimpr. 1997, pp. 292 y ss; SCHMALZ, Grundrechte, Baden-Baden, 1997, pp. 50 y ss ha utilizado la expresión ("Grundrechtseingriff"), si bien algún autor como SCHWABE, Grundkurs Staatsrecht, Berlín-New York, 1995, pp. 90 y ss, se refiere ellas como «limitaciones» o «restricciones» («Beschränkungen») o («Einschränkungen»).

13 Teoría de los..., op. cit., pp. 296 y 297, quien efectúa dichas afirmaciones respecto de las normas iusfundamentales y, en concreto, de aquellas que otorgan derechos de defensa. Dada la importancia de la tesis de Alexy en este trabajo, cabe afirmar que, en su obra en español, se ha traducido «Schanken» (límites) como «restricción» y «Eingriff» (intromisión, intervención o injerencia y, asimismo, restricción) como «intervención». Asimismo, ECKHOFF, Der Grundrechtseingriff..., op. cit., p. 22 señala que cuando existe una intromisión en el ámbito de protección se cumple el supuesto de hecho del derecho fundamental, se activa el efecto protector de tal derecho fundamental, en cuyo caso debe aplicarse la consecuencia jurídica, como es la necesidad de que se justifique la intromisión a través de los límites a los derechos fundamentales.

${ }_{14}$ SCHMALZ, Grundrechte..., op. cit., p. 63. 
de hecho de dicha norma de derecho fundamental (art. 18.2 CE). Ello conlleva una consecuencia jurídica como es que se activa el efecto protector del derecho fundamental a la inviolabilidad del domicilio, lo que nos lleva a afirmar que existe un derecho a que prima facie no se intervenga sobre dicho domicilio, esto es, a que dichas intromisiones están en principio prohibidas. En este sentido, el propio art. 18.2 CE declara «el domicilio es inviolable. Ninguna entrada o registro podrá hacerse en él sin... salvo...». Es, entonces, cuando surge la necesidad de justificación en virtud de un límite, en cuyo caso, si, en efecto, se justifica constitucionalmente, el acto procesal podrá considerarse como una medida restrictiva y, por ello, legítima desde el punto de vista de nuestra Constitución. Si no estuviese justificada ex Constitutione, se trataría de una actuación definitivamente vulneradora del derecho fundamental a la inviolabilidad del domicilio. Así, el propio art. 18.2 CE indica, «...podrá hacerse en él sin consentimiento del titular o resolución judicial, salvo en caso de flagrante delito». Ello significa que si la entrada o registro se ha llevado a cabo con el consentimiento del titular o en virtud de alguno de los dos límites indicados, de un lado, un límite formal, como es la resolución judicial o, de otro, material, como es el supuesto del delito flagrante (sin perjuicio de que asimismo sea respetuosa con el principio de proporcionalidad, el cual, como veremos en el epígrafe II de este trabajo se encuentra implícitamente reconocido en el art. 18.2 CE), dicha entrada o registro domiciliario será una medida constitucionalmente legítima y, en consecuencia, podrá considerarse como una medida restrictiva del derecho fundamental a la inviolabilidad del domicilio. Y todo ello, con las favorables consecuencias procesales y, en particular, probatorias, que ello conlleva.

De acuerdo con el expuesto concepto "Grundrechtseingriff" debieran asimismo tomarse en cuenta las distintas expresiones que, al igual que nuestra Constitución, prevé la Ley Fundamental de Bonn ${ }^{15}$, para referirse a la idea de menoscabo o limitación de derechos fundamentales. Tales términos son «restricción " ("eingegriffen») (respecto al derecho a la vida y a la integridad física, en el art. 2 II 3), «limitación» ("Eingeschränkt») (en relación con la libertad de circulación y residencia, en el art. 11 II; respecto a la libertad de abandonar el ejercicio de una profesión o puesto de trabajo, en el art. 12 a VI; en relación con el derecho a expresar y difundir libremente la opinión, así como a la libertad de circulación, de residencia y de inviolabilidad del domicilio, en materia de defensa

${ }_{15} \mathrm{Al}$ igual que en nuestra CE, en la Ley Fundamental de Bonn, no se utiliza expresamente ninguno de estos términos jurídicos, en algunos casos, tal y como acontece por ejemplo, con el registro de un domicilio inviolable (art. 13 GG), si bien lógicamente ha de constituir igualmente restricciones de los derechos fundamentales. 
y servicio sustitutorio, en los arts.17 a I y II, respectivamente; respecto a los derechos fundamentales en general, en el art. 19 I 1 GG), «limitación» («Beschränkung») (en cuanto a la libertad de reunión en el art. 8 II; respecto al secreto epistolar, postal y de telecomunicaciones, en el art. 10 II; en cuanto a la libertad, en el art. 104 I GG) o "límite» ("Schranke») (en cuanto a la libertad de opinión, en el art. 5 II; en relación con el derecho de propiedad, de herencia y expropiación, en el art. 14 I 2 GG).

Así, pues, identificado el concepto de "Grundrechtseingriff», se ha formulado su contenido y, en particular, los requisitos que lo conforman, como son, de un lado, el cumplimiento del supuesto de hecho del derecho fundamental, pues ha tenido lugar una intromisión en un ámbito constitucionalmente protegido y, de otro, la justificación constitucional de tales intromisiones en principio vulneradoras del derecho. Tales requisitos se van a tomar en cuenta a la hora de exponer el concepto de restricción de los Derechos Fundamentales en nuestro ordenamiento jurídico, tal y como se indicará más adelante.

\section{B) La evolución de la «Grundrechtseingriff» y su repercusión en España}

La adopción del concepto utilizado en Alemania («Grundrechtseingriff»), por nuestra parte, con el fin de formular la noción de «restricción de los Derechos Fundamentales», presenta aun algún inconveniente. Ante la ampliación que los derechos fundamentales han sufrido en su campo de actuación, motivada por la aparición de las nuevas formas de ser violados ocasionada por la omisión estatal de su deber de garantizarlos, el concepto clásico de "Grundrechtseingriff» ha entrado en crisis. Si, como ha señalado Bleckmann ${ }^{16}$, dicha noción constituye una figura dogmática orientada a la búsqueda de los criterios más adecuados para garantizar una protección eficaz de los derechos fundamentales en aquellos casos en que son objeto de limitaciones, tal mecanismo jurídico tiene que tomar en cuenta las nuevas formas de violación que vayan surgiendo. Con el objeto de exponer dicha evolución y su repercusión en nuestro sistema, han de plantearse dos cuestiones.

En primer lugar, cabe recordar cuáles son las nuevas formas de violación de los derechos fundamentales, que constituyen la causa de la evolución del concepto; para ello, se toma como punto de referencia la evolución de los derechos fundamentales en Alemania y, asimismo, y al hilo de tal exposición, se constata que los aspectos que han provocado en dicho país este cambio, se recogen asimismo en la jurisprudencia de nuestro Tribunal Constitucional.

16 Staatsrecht II. Die Grundrechte, Köln, Berlín, Bonn, München, Keymann, 1989, p. 327. 
En segundo término, ha de plantearse por qué los novedosos supuestos de violación mencionados han provocado la revisión del concepto clásico de restricción de derechos fundamentales.

a) Las nuevas formas de violación derivadas del incumplimiento del deber de protección estatal

Como consecuencia del paso del Estado Liberal al Social, los derechos fundamentales pueden resultar vulnerados, no sólo a través de actuaciones positivas de los poderes públicos, que incumplen con la obligación de respetarlos, sino además frente al incumplimiento de la obligación de garantizar tales derechos ( Schutzpflicht») ${ }^{17}$. Admitida, con la anterior afirmación, la doble vertiente de los derechos fundamentales, esto es, la tradicional dimensión subjetiva junto con la nueva objetiva que, desde principio de los años ochenta, ha reconocido nuestro Tribunal Constitucional ${ }^{18}$, se ha ocasionado un cambio en el destinatario ( Adressat»), así como en la función ( Funktion») de los derechos fundamentales ${ }^{19}$. De conformidad con la doble modificación señalada, tales derechos se salvaguardan, no sólo frente a las violaciones de los poderes públicos, sino además frente a las vulneraciones provenientes de los particulares y, asimismo, no se consideran únicamente como ámbitos de libertad frente al Estado, sino también como normas objetivas que deben garantizarse por todo el ordenamiento jurídico y político.

El estudio de la segunda modalidad de violación, las que se ocasionan por la omisión de los poderes públicos ${ }^{20}$, se facilita con la previa formulación de las razones por las que ha surgido tal deber estatal, lo que permitirá exponer, en segundo lugar y de forma sistematizada, los nuevos supuestos de violación.

17 El origen del «Schutzplichten» o «Schutzgebote» se sitúa en la BVerfGE 39, 1 (42) que declaró inconstitucional la ley de modificación del Código Penal en materia de aborto. En este sentido, vide VON MÜNCH;FERRER I RIBA, en SALVADOR CODERCH (Coord.), Asociaciones, derechos fundamentales y autonomía privada, Madrid, 1997, pp. 94 y 95 -en nota 48.

18 A este respecto, se pueden consultar las SSTC 25/1981, 14 de julio (FJ 5०); 114/1984, de 29 de noviembre $\left(\mathrm{FJ} 4^{\circ}\right) ; 53 / 1985$, de 11 de abril (FJ $\left.4^{\circ}\right) ; 159 / 1986$, de 12 de diciembre $\left(\mathrm{FJ} 6^{\circ}\right.$ ); 245/1991, de 16 de diciembre (FJ 5); 81/1998, de 2 de abril (FJ $2^{\circ}$ ) y AATC 382/1996, de 18 de diciembre $\left(\mathrm{FJ} \mathrm{3} 3^{\circ}\right) ; 333 / 1997$, de 13 de octubre $\left(\mathrm{FJ} 3^{\circ}\right.$ ).

19 PIEROTH; SCHLINK, Grundrechte. Staatsrecht II, Heidelberg, 1993, p. 65

20 Conviene apuntar, sin que sea objeto de análisis, que incluso podrían analizarse las nuevas formas de violación derivadas del incumplimiento del deber de protección del Estado conforme a la distinción entre derechos fundamentales de autonomía y derechos de prestación. 
a') Causa del deber: la vertiente objetiva de los Derechos Fundamentales

Teniendo en cuenta que los nuevos supuestos de vulneración de los derechos fundamentales se originan por el reconocimiento de su dimensión objetiva, conviene explicar la relación que opera entre ambos aspectos, en la medida en que resulta de utilidad para determinar las repercusiones que ello supone sobre el concepto de «restricción de los Derechos Fundamentales».

Conforme a la nueva dimensión objetiva señalada, los derechos fundamentales, no sólo se consideran como derechos de defensa ("Abwehrrechte»), en un sentido clásico o como garantía institucional, frente a las intromisiones estatales, sino que además, conectados en una relación, no tanto de yuxtaposición, cuanto de sumisión y reciprocidad ${ }^{21}$, adquieren una nueva «cualidad $»^{22}$ como normas objetivas que expresan un contenido axiológico o decisiones de valor objetivas ("objektiven Wertentscheidung») de validez universal.

En efecto, constituye el punto de partida para llegar al reconocimiento de la doble vertiente de los derechos fundamentales, subjetiva y objetiva, la aparición de la denominada dimensión axiológica de tales derechos que surgió en el Ordenamiento Alemán a mediados de los años 50, en conexión con la obligada discusión suscitada en torno a la fundamentación última del Derecho que se originó en la República Federal tras la caída del Régimen Nacional-Socialista y la crisis del positivismo ${ }^{23}$. Como consecuencia del reconocimiento de dicho contenido axiológico de los derechos fundamentales, los valores que inspiran tales derechos se transmiten hacia todos los sectores de ordenamiento, lo que ha sido denominado en el país germano como "efecto de irradiación» ("Ausstrahlungswirkung»). Con tal expresión se quiere señalar la influencia de los derechos fundamentales sobre el Derecho ordinario ${ }^{24}$, penal civil, laboral y administrativo, que opera respecto de los tres poderes del Estado, legislativo, ejecutivo y judicial de manera que actúa sobre la Administración, el poder legislativo en su labor reguladora y sobre el juez en el momento de interpretar y aplicar las normas

21 HESSE, Manual de Derecho Constitucional, Madrid, 2. a ed., 2001, p. 91.

22 BÖCKENFÖRDE, Escritos sobre Derechos..., op. cit, p. 109; SCHMALZ, Grundrechte..., op. cit., p. 106 afirma el significado de los derechos fundamentales como «decisiones de valor objetivas" ("objektiv-rechtliche wertentscheidungen»).

23 BÖCKENFÖRDE, Escritos sobre Derechos..., op, cit., p. 105, señala que, a tal fin, se reactivaron o reactualizaron dos teorías: la «idea material del valor» tal y como operó en la filosofía de los valores en Scheler y Hartmann, y la teoría axiológica de los derechos fundamentales, procedente de la época de Weimar, de Smend.

${ }^{24}$ HESSE, Manual de Derecho..., op. cit., p. 91. 
de Derecho ordinario ${ }^{25}$. Por tanto, la vinculación a la legislación, administración y la jurisdicción (art. 1.3 GG) es doble ${ }^{26}$, no sólo en un sentido negativo como un deber de abstención de los poderes públicos, sino además como una obligación positiva dirigida al Estado, que consiste en hacer efectivo el contenido de los derechos fundamentales.

Las vulneraciones de los derechos fundamentales ocasionadas por el incumplimiento del Estado de la obligación positiva de garantizarlos son igualmente reconocidas en nuestro ordenamiento, como consecuencia de su consideración como fundamento jurídico-político del ordenamiento jurídico en su conjunto, aspecto que constituye la dimensión objetiva de los derechos fundamentales. En particular, el deber positivo de actuación derivado de tal vertiente objetiva fue asumido tempranamente, junto con la dimensión subjetiva, por nuestro Tribunal Constitucional ${ }^{27}$ y secundado por un sector de la doctrina ${ }^{28}$. Se deriva igualmente de la influencia que tales derechos ejercen sobre el sistema jurídico respecto de los tres poderes del Estado, originada por el efecto de irradiación de los valores que fundamentan los mencionados derechos sobre todos los sectores del ordenamiento. Tal dimensión axiológica de los derechos fundamentales, se refiere al hecho de que constituyen la manifestación más sobresaliente del sistema valorativo constitucionalmente consagrado ${ }^{29}$ y, por ello, informan el conjunto de la organización jurídica y política. Por este motivo, si los poderes públicos no logran garantizar estos derechos en todos los sectores del ordenamiento jurídico, lo será porque, entre otros motivos, han actuado involuntariamente, o sin que un límite justifique su actuación, como ocurre, por ejemplo, en el caso de una intervención de las comunicaciones sin una resolución judicial que la acuerde e, incluso, porque un particular viole el derecho fundamental de otro individuo sin que el correspondiente órgano jurisdiccional competente para resolver el conflicto así lo reconozca en la sentencia que ponga fin al conflicto. Finalmente, conviene constatar que el reconocimiento de la do-

25 BÖCKENFÖRDE, Escritos sobre Derechos..., op. cit., p. 111.

${ }^{26}$ HESSE, Manual de derecho..., op. cit., p. 94.

27 Vid supra nota ${ }^{\circ} 18$.

${ }^{28}$ DIEZ PICAZO, "Constitución, ley, juez», REDC, sep-dic 1985, p. 19; FERNANDEZ SEGADO, «La teoría jurídica...», op. cit., p. 201; PRIETO SANCHÍS, «Sobre el concepto...», op. cit., pp. 269-270.

${ }_{29}$ Son los valores superiores proclamados en el art. 1.1 CE, esto es, la libertad, justicia, igualdad y pluralismo político. Se podría cuestionar asimismo la consideración, como valor, de la dignidad humana o, incluso, la seguridad jurídica y la solidaridad, como considera Peces-Barba. Sobre esta cuestión, vide, DÍAZ REVORIO, Los valores superiores en la Constitución Española, Madrid, 1997, pp. 114-127. 
ble dimensión de los derechos fundamentales no constituye un desarrollo previo, sino conforme a la constitución, tal y como se deriva del artículo 10.1 de la Constitución ${ }^{30}$.

Ahora bien, la evolución sufrida por los derechos fundamentales ante la aparición de la dimensión objetiva, ha llevado a cuestionarse hacia quién debe dirigirse principalmente este deber de protección. En última instancia se cuestiona, como ha señalado Bockenförde ${ }^{31}$, si, bien el Legislador, bien el Tribunal Constitucional tienen que conformar el ordenamiento jurídico en cuanto a sus contenidos sustanciales. La elección de una u otra alternativa depende respectivamente de en qué vertiente, subjetiva u objetiva se coloque el acento. En particular, dicha discusión se ha originado porque el reconocimiento de la dimensión objetiva de los derechos fundamentales ha provocado el paso del estado parlamentario al estado jurisdiccional de jurisdicción constitucional ${ }^{32}$. Sin embargo, este cambio ha sido objetado pues provoca un uso inflacionista de los derechos fundamentales ${ }^{33}$, habida cuenta que prácticamente cualquier conflicto jurídico puede ser subsumido en un derecho fundamental y acceder, por ello, al Tribunal Constitucional, a través del correspondiente recurso amparo, con la sobrecarga de trabajo que ello puede suponer. Para evitarlo, se ha propuesto ${ }^{34}$ que el Legislador establezca los presupuestos y efectos de la influencia de los derechos fundamentales en el ordenamiento jurídico, pues con ello se incrementa la seguridad jurídica respecto de la interpretación y aplicación que el juez ordinario puede hacer directamente de cada derecho fundamental. Asimismo, y de esta manera, el Tribunal Constitucional descenderá su nivel de trabajo, puesto que no tendrá que controlar, tanto la aplicación de las normas, porque se vulnere un Derecho constitucional sustantivo, limite el derecho de acceso a la jurisdicción o incurra en irrazonabilidad, arbitrariedad o error patente, cuanto el control de las normas mismas. Así, pues, la evolución sufrida por esta vertiente objetiva puede llevar a considerar principalmente al Poder Legislativo como el destinatario de tal deber de protección.

30 Señala el TC en STC 25/1981, de 14 de julio (FJ 5º que esta doble concepción de derechos fundamentales se recoge en el art. 10.1 CE. Si bien, también pueden considerarse incluidos en el art. 9 CE.

31 Escritos sobre Derechos..., op. cit., p. 138.

32 BÖCKENFÖRDE, Escritos sobre Derechos..., op. cit., p. 134.

33 HESSE, Derecho Constitucional y..., op. cit., p. 67.

${ }^{34}$ HESSE, Derecho Constitucional y..., op. cit., pp. 63, 54 y 65. 
b') Los nuevos supuestos de violación

Expuesto el fundamento de los nuevos supuestos de violación, podemos afirmar que todos ellos se residencian en el artículo 10.1 de nuestra Constitución. En efecto, puesto que constituyen casos de incumplimiento del deber de protección derivados de la dimensión objetiva de los derechos fundamentales, y dado que tal dimensión se proclama en dicho precepto, puede afirmarse que todos los casos que se exponen a continuación se contienen en el señalado artículo, sin perjuicio de que, otros supuestos específicos puedan derivarse asimismo de otros preceptos constitucionales. En particular, hemos de distinguir los tres grupos de violaciones que se exponen a continuación. He elegido esta clasificación porque facilita su correlación con las nuevas pautas de «intromisión» que, de esta triple distribución, se derivan.

En el primer grupo, se incluyen una serie de supuestos que tienen en común que se tratan de conflictos entre el Estado y los particulares donde los poderes públicos han incumplido su deber de protección porque no han garantizado suficientemente el derecho fundamental. Como veremos más adelante ${ }^{35}$, tales supuestos se corresponden fundamentalmente con las que he denominado «intromisiones involuntarias» e «intromisiones fácticas».

El segundo y tercer grupo, se compone, a su vez, de aquellos casos en los que el Estado vulnera por "omisión» los derechos fundamentales de los particulares, debido a que dichos poderes públicos no reconocen su vigencia entre dichos sujetos. Y, ello, tanto si los particulares se encuentran o no vinculados jurídicamente. Tales casos se correlacionan con las que he calificado como «intromisiones mediatas». A continuación, se examinan los tres grupos de violación con más detalle.

a“) Entre el Estado y los particulares: violaciones involuntarias y fácticas y las omisiones del Poder Ejecutivo

Como ya he señalado, en el primer grupo, se engloban una serie de supuestos que presentan como común denominador que constituyen conflictos entre el Estado y los particulares, donde los poderes públicos han incumplido su deber de protección al no haber garantizado suficientemente el derecho fundamental. A su vez, pueden distinguirse dos grupos de vulneraciones: de un lado, aquellas ocasionadas por el Estado porque no ha operado con la diligencia debida, bien porque el resultado se ha ocasionado de forma involuntaria, bien porque tal ac-

35 Vide infra I. 2. B) 
tuación no revestía forma jurídica alguna; y, de otro, aquellas omisiones provenientes del Poder Ejecutivo.

Respecto de las violaciones involuntarias y fácticas, que conforman el primer subgrupo, en la jurisprudencia del BVerwG se han planteado algunos casos. En particular, el supuesto, por ejemplo, del disparo involuntario efectuado por un policía ${ }^{36}$, o una actuación jurídica de la administración en virtud de la cual se autoriza el proyecto de construcción de una calle. En este segundo ejemplo, si bien el incremento de los niveles de ruido ocasionado con el tránsito de los automovilistas que utilizan esa carretera era previsible, el efecto ocasionado, la violación del derecho al libre desarrollo de la personalidad de los ciudadanos, no fue el inicialmente pretendido, lo que ocasiona un resultado no pretendido ${ }^{37}$.

En cuanto al segundo subgrupo, las omisiones provenientes del poder ejecutivo $^{38}$, el TC se ha planteado algunos casos. En la STC 254/1993, de 20 de julio $^{39}$, ante el reconocimiento de la dimensión positiva del derecho a la intimidad, se cuestionó si la negativa administrativa a comunicar información solicitada sobre datos de carácter personal existentes en ficheros automatizados de la Administración del Estado, vulnera el artículo 18.1 y 18.4 de nuestra Carta Magna. Posteriormente, en la STC 143/1994, de 9 de mayo ${ }^{40}$ se planteó, previo reconocimiento de la dimensión positiva del derecho a la intimidad, un caso de violación del artículo 18.4 de nuestra Constitución ante la supuesta ausencia de garantías sobre el uso de la información obtenida a través de las operaciones identificadas con el NIF.

b“) Entre particulares no vinculados jurídicamente

En el segundo grupo de violaciones, hemos de señalar aquellas motivadas por el hecho de que los poderes públicos hayan omitido el deber de garantizar la

36 BVerwGE 87, 37 (42), cit. en SCHMALZ, Grundrechte..., op. cit., p. 55.

37 BVewGE 90, 112 (120), cit. en SCHAMLZ, Grundrechte..., op. cit., p. 56.

38 En este apartado se plantean únicamente las omisiones del poder ejecutivo y se excluyen las procedentes del poder legislativo y judicial por dos razones: 1) las omisiones procedentes del poder legislativo se encuentran excluidas del recurso de amparo; tan sólo pueden fundamentar una pretensión de amparo las omisiones del poder ejecutivo y judicial; 2) de ellas, a su vez, cabe excluir, de este grupo, a las provenientes del poder judicial porque, en última instancia, derivan de un conflicto entre particulares, por lo que serán analizadas en los dos grupos siguientes.

39 STC 254/1993, de 20 de julio (FJ $7^{\circ}$ ).

40 La supuesta violación ha sido cometida por una disposición reglamentaria, el RD 357/1990, de 9 de marzo, y la Orden de 14 de marzo de 1990 que regulan la composición y forma del NIF y tarjeta acreditativa del mismo $\left(\mathrm{FJ} 9^{\circ}\right)$. 
vigencia de los derechos fundamentales entre particulares, no vinculados jurídicamente, que tienen lugar en el ámbito penal, civil y administrativo.

Se ha planteado ante el BVerfG el deber de protección del Estado de la vida humana en el caso del aborto ${ }^{41}$; en el caso Schleyer ${ }^{42}$, en el que un individuo secuestrado fue asesinado porque el Estado no se sometió a sus chantajes; en el caso de medidas estatales contra la propagación del SIDA; o en la protección pública frente a peligros derivados del funcionamiento de centrales nucleares y peligros similares. Nuestro Tribunal Constitucional se planteó igualmente, en el orden jurisdiccional penal, el caso del aborto ${ }^{43}$.

En el ámbito civil se han suscitado diferentes conflictos entre la libertad de expresión y el derecho al honor. Así, el conflicto entre ambos derechos se resuelve en la STC 3/1997, de 13 de enero ${ }^{44}$, cuya titularidad recae sobre dos particulares, en la que se recurre una sentencia del Tribunal Supremo que, a su vez, resolvía una intromisión sobre el derecho al honor de uno de ellos; en la STC 231/1988, de 2 de diciembre ${ }^{45}$ se invoca la violación del derecho a la imagen e intimidad a causa de la difusión de una cinta de video por parte de una empresa privada. Asimismo, en la STC 171/1990, de 5 de noviembre ${ }^{46}$, se plantea un conflicto entre dos particulares no vinculados jurídicamente $y$, en concreto, entre el derecho a una comunicación libre e información veraz así como el derecho a la tutela judicial efectiva, cuya violación se invoca, y el derecho al honor e intimidad personal y familiar.

En el ámbito administrativo, el Tribunal Constitucional no admitió a trámite una pretensión de amparo introducida por un particular en la que alegaba la violación del derecho fundamental a la inviolabilidad del domicilio, originada por la contaminación al medio ambiente que una empresa había ocasionado, lo que hizo peligrar gravemente la salud del recurrente. En tal caso, el demandante, en primer lugar, se había dirigido contra la Administración, que no estimó tal pretensión, y, tras agotar la vía ordinaria y constitucional, consideró que los sucesivos órganos jurisdiccionales habían infringido su derecho a la protección del domicilio, por lo que, finalmente, acudió al TEDH. El citado Tri-

${ }^{41}$ BVerfGE 39,1 (42), cit. en VON MÜNCH; FERRER I RIBA, en SALVADOR CO-

DERCH (Coordinador), Asociaciones, derechos fundamentales..., op. cit., p. 94, en nota 48.

${ }^{42}$ BVerfGE 46, (120), cit. en VON MÜNCH; FERRER I RIBA, en SALVADOR CO-

DERCH, (Coordinador), Asociaciones, derechos fundamentales..., op. cit., p. 46.

43 STC 53/1985, de 11 de abril (FJ $\left.4^{\circ}\right)$.

44 STC $3 / 1997$, de 13 de enero (FJ $1^{\circ}$ ).

45 STC 231/1988, de 2 de diciembre (FJ $3^{\circ}$ ).

46 STC 171/1990, de 5 de noviembre (FJ $4^{\circ}$ ). 
bunal, en el «Asunto López Ostra» ${ }^{47}$ estimó la violación del art. 8 CEDH relativo a la protección de la vida privada y del domicilio, lo que provocó que, posteriormente, el Tribunal Constitucional ${ }^{48}$ asumiese el contenido de la sentencia «López Ostra».

c“) Entre particulares sometidos a una relación jurídico-privada

Finalmente, caben destacar los supuestos de «eficacia mediata de los derechos fundamentales entre particulares» ("Mittelbare Drittwirkung der Grundrechte»), en los que la violación se atribuye a una omisión estatal del deber de garantizar los derechos fundamentales entre particulares sometidos a una relación jurídicoprivada $^{49}$. La eficacia de los derechos fundamentales entre particulares constituye una creación doctrinal alemana ${ }^{50}$, que distingue entre la inmediata («unmittelbare») y mediata («mittelbare»), asumida por la jurisprudencia del $\mathrm{BVerfG}^{51}$. Esta teoría no plantea problemas en cuanto a su reconocimiento constitucional, porque puede entenderse proclamada en los artículos 9.1 y 10.1 de nuestra Constitución ${ }^{52}$.

En particular, el problema se suscita en cuanto a la determinación del alcance de tal eficacia, respecto a lo cual la mayoría de la doctrina, así como la jurisprudencia constitucional alemana, salvo la excepción prevista en el artículo 9.3

47 STEDH «Asunto López Ostra» de 9 de diciembre de 1994.

48 SSTC 199/1996, de 3 de diciembre (FJ $4^{\circ}$ y $6^{\circ}$ ), 119/2001, de 24 de mayo (FJ $6^{\circ}$ y $7^{\circ}$ ); 16/2004, de 23 de febrero (FJ $4^{\circ}$ ).

49 Aunque la teoría de la "Drittwirkung der Grundrechte» y el deber positivo del Estado constituyen construcciones afines porque se refieren a la eficacia de los derechos fundamentales entre particulares, han sido diferenciadas por la doctrina alemana desde un punto de vista dogmático para incluir, bajo la primera, aquellos casos donde los particulares están vinculados jurídicamente y, al amparo de la segunda, los supuestos en los que no existe vínculo jurídico alguno entre ellos. Tal distinción ha sido puesto de relieve por VON MÜNCH; FERRER I RIBA, en SALVADOR CODERCH (Coord.), Asociaciones, derechos fundamentales..., op. cit., pp. 45-49.

50 Se considera que la teoría de la "Drittwirkung der Grundrechte» fue elaborada por Nipperdey, Presidente del Tribunal Laboral Federal que por ello introdujo esta tesis el citado tribunal, lo que justifica la relación entre doctrina y jurisprudencia.

51 BVerfGE 7, 198, creadora de la teoría de la «mittelbare Drittwirkung der Grundrechte» o eficacia indirecta de los Derechos Fundamentales. Con posterioridad, los casos planteados ante el BVerfG constituyen en su mayoría conflictos originados en el ámbito laboral y en el derecho de familia o de sucesiones, tal y como han explicado VON MUNICH; FERRER I RIBA, en SALVADOR CODERCH (Coord.), Asociaciones, derechos fundamentales..., op. cit., pp. 35-42.

52 GIMENO (con CASCAJO), El recurso de amparo, Madrid, 2a ed., 1988 (imp. 1992), p. 129. 
GG, no ha reconocido efecto directo a los derechos fundamentales entre particulares, sino que admite su eficacia mediata, según la cual la violación se atribuye a un poder público ${ }^{53}$. La doble teoría ha sido incorporada por nuestra doctrina ${ }^{54}$ que, en su mayoría, admite la eficacia mediata, si bien igualmente, en nuestro país, se discute su alcance. En este sentido, conforme a la distinción formulada, en cuanto a la eficacia de los derechos fundamentales entre particulares, entre un punto de vista material y procesal ${ }^{55}$ cabe señalar que, si bien el particular puede deducir su pretensión ante los tribunales ordinarios, formalmente no puede acudir ante el Tribunal Constitucional. Esta carencia de legitimación pasiva de los particulares no impide sin embargo que el Tribunal Constitucional pueda revisar la actuación de tales tribunales. En efecto, el particular al que se le ha vulnerado el derecho, si bien no ostenta legitimación para invocar el amparo constitucional, puede deducir su pretensión ante los tribunales ordinarios de manera que, si tales órganos jurisdiccionales no garantizan el contenido del derecho fundamental, tiene lugar una violación por omisión imputable a los expresados órganos jurisdiccionales, en cuyo caso la resolución dictada es susceptible de ser invocada en amparo constitucional en virtud del artículo 44.1 LOTC.

Respecto de estos casos de eficacia mediata de los derechos fundamentales entre particulares vinculados jurídicamente se han planteado numerosos supuestos, fundamentalmente en el ámbito laboral, resueltos por nuestro Tribunal Constitucional $^{56}$. En las sentencias que se destacan a continuación se plantea un

53 Sobre la elaboración de la «Drittwirkung der Grundrechte» por parte de la doctrina alemana y su aplicación por el Tribunal Constitucional Federal, puede leerse a GARCÍA TORRES; JIMÉNEZ BLANCO, Derechos Fundamentales y relaciones entre particulares, Madrid, 1986, pp. 1939.

${ }^{54}$ La teoría de la "Drittwirkung der Grundrechte» ha sido estudiada en nuestro país por GARCÍA TORRES; JIMENEZ BLANCO, Derechos Fundamentales y..., op. cit., pp. 19 y ss; DE LA QUADRA-SALCEDO, El recurso de amparo y los derecho fundamentales en las relaciones entre particulares, Madrid, 1981, pp. 48-79; BILBAO UBILLOS, La eficacia de los derechos fundamentales frente a particulares, Madrid, 1997, pp. 277-382.

55 Tal doble distinción ha sido efectuada por GIMENO (con CASCAJO), El recurso de... pp. 129 y 130. Así, pues, se afirma que rige la teoría de la eficacia directa de la «Drittwirkung» ante los Tribunales ordinarios, mientras que ante el Tribunal Constitucional se aplica la teoría de la eficacia mediata, dada la dicción literal de los artículos 53.1 de nuestra Carta Magna así como del artículo 161.1 b) que remite al artículo 53.2 del referido Texto Constitucional, precepto íntimamente relacionado con el artículo 41.2 de la LOTC y, especialmente, en virtud el contenido del artículo 44.1 de la señalada disposición.

56 Se han planteado supuestos de «eficacia inmediata de los derechos fundamentales entre particulares ("Unmittelbare Drittwirkung») fundamentalmente en el ámbito laboral. En este sentido, SSTC 2/1982, de 29 de enero, 78/1982, de 20 de diciembre; 35/1983, de 11 de mayo; 
conflicto entre el empleador y el empleado que fue resuelto mediante sentencia, en la que se declara procedente el despido, y a la que es imputable la violación (indirectamente ocasionada) del correspondiente derecho fundamental, en la medida en que dicha resolución no reconoció la eficacia del derecho en cuestión entre los particulares en conflicto. Así, se entienden vulnerados los derechos del trabajador, contenidos en el art. 18.1 CE, en las SSTC 170/1987, de 30 de octubre, 99/1994, de 11 de abril (derecho a la propia imagen) y el derecho a la libertad de expresión en las SSTC 186/1996, de 25 de noviembre, 151/2004, de 20 de septiembre, 198/2004, de 15 de noviembre, 181/2006, de 19 de junio (FJ $6^{\circ}$ ) y en la 56/2008, de 14 de abril.

Como consecuencia de ello, en la medida en que los poderes públicos pueden vulnerar los derechos fundamentales debido al incumplimiento de su deber de protegerlos, no cabe tomar en consideración únicamente las tradicionales intromisiones finales, jurídicas e inmediatas. Ello implica, como se explicará a continuación, que los tres tipos de intromisiones mencionadas han de revisarse y, en consecuencia, el concepto clásico de Grundrechtseingriff.

\section{b) La crisis del concepto clásico de «Grundrechtseingriff»}

Ante las nuevas formas de violación señaladas, el concepto clásico de «Grundrechtseingriff", que se formuló tomando en cuenta tan sólo la vertiente subjetiva de los derechos fundamentales, ha devenido insuficiente. Con el mencionado concepto tradicional se pretendían encontrar criterios justos con los que se pudiese determinar qué medidas estatales resultaban apropiadas para lograr una eficaz protección de los derechos de defensa. Ante la nueva concepción objetiva, tales criterios se han cuestionado parcialmente y se han formulado nuevas pautas por parte de la doctrina que han provocado la ampliación del originario concepto clásico.

Conforme a la noción clásica, $\mathrm{Schmalz}{ }^{57}$ ha manifestado que el requisito mínimo para que se produzca una intromisión lo constituye la relación de «causalidad» entre el acto y la afección del bien jurídico. Para ello, un sector de la doc-

55/1983, de 26 de junio; 18/1984, de 7 de febrero; 88/1985 de 19 de junio; 170/1987, de 30 de octubre; 177/1988, de 10 de octubre (FJ $4^{\circ}$ ); 99/1994, de 11 de abril; 6/1995 de 10 de enero; 106/1996 de 12 de junio; 186/1996, de 25 de noviembre (FJ $3^{\circ}$ ) y ATC 333/1997, de 13 de octubre $\left(\mathrm{FJ} 3^{\circ}\right.$ ) señala que «en suma, apostillábamos en la STC 382/1986 (FJ $3^{\circ}$ ), antes que la propia conducta de los particulares "per se», lo que se recurre en amparo y, en consecuencia, lo que debe ser objeto de control no es, genuinamente, sino la falta de tutela de los derechos fundamentales por parte de la resolución judicial impugnada».

57 Grundrechte..., op. cit., p. 55. 
trina alemana ${ }^{58}$ ha señalado que las intromisiones tienen que cumplir básicamente tres condiciones como es que sean directas, finales y jurídicas. Junto con tales requisitos, Bleckmann ${ }^{59}$ ha añadido un cuarto caso derivado del hecho de que la intromisión tenga que revestir un carácter jurídico. Este supuesto implica una doble exigencia: de un lado, se presupone el carácter jurídico del acto del Estado y, de otro, se exige que el acto regule la relación jurídica entre el Estado y el titular del derecho afectado. Incluso, se ha incluido ${ }^{60}$ una quinta condición que exige que tales medidas se efectúen mediante una orden ("Befehl») o a través de la coacción ( ZZwang»). Sin embargo, dado que cabe afirmar que el Estado vulnera un derecho fundamental cada vez que omite el deber de salvaguardarlos, bien porque en su actuación frente a particulares no actúa con la diligencia debida, u omite cualquier actuación, bien porque por omisión no reconoce la vigencia de un derecho fundamental entre particulares vinculados o no jurídicamente, cabe afirmar que tales criterios clásicos no comprenden estas nuevas manifestaciones. Por tanto, ha de plantearse la posibilidad de que constituyan intromisiones de derechos fundamentales, no sólo las actuaciones vulneradoras en las que exista intención o finalidad, sino también las intromisiones involuntarias y, por ello, no únicamente jurídicas sino además fácticas; $y$, finalmente, no sólo intromisiones inmediatas, sino también las que se ocasionan de forma mediata.

Así, pues, si se toman en cuenta las soluciones dadas al doble problema que suscita la formulación de concepto de «restricción de los Derechos Fundamentales», cabe concluir que dicha noción se va a definir tomando en cuenta el concepto alemán equivalente ("Grundrechtseingriff), comprensivo, tanto de su vertiente clásica o subjetiva, como de la objetiva, que es aquella que toma en cuenta los distintos supuestos de violación de los derechos ocasionadas ante la «omisión» de los poderes públicos de su deber de garantizarlos.

\section{La nueva concepción de la «restricción de los Derechos Fundamentales»}

Una vez justificada, no sólo la aparición de una nueva concepción de la «restricción de los Derechos fundamentales» ("Grundrechtseingriff), que ha sido

58 BLECKMANN, Staatsrecht II. Die Grundrechte, Köln, Berlín, Bonn, München y Heymann, 1989, p. 336; ECKHOFF, Der Grundrechtseingriff..., op. cit., p. 21; PIEROTH;SCHLINK, Grundrechte. Staatsrecht II..., op. cit., p. 64 ; SCHMALZ, Grundrechte..., op. cit., p. 55

59 Staatsrechts II. Die Grundrechte..., op. cit., pp. 336 y 337.

${ }^{60}$ BLECKMANN, Staatsrecht II. Die Grundrechte..., op. cit., p. 337; PIEROTH;SCHLINK, Grundrechte. Staatrecht II..., op. cit., p. 55. 
calificada por Eckhoff ${ }^{61}$ como «la concepción independiente de la restricción de derechos fundamentales» ("die Eingriffsunabhängige Konzeption»), sino también el suficiente apoyo doctrinal y jurisprudencial en nuestro país para incorporarlo, al igual que ha sido asumido por la doctrina de otros países europeos como Portugal $^{62}$ bajo la expresión "restriçao de direitos», cabe exponer su concepto.

\section{A) Concepto}

En este sentido, y tomando en cuenta el concepto alemán anteriormente trascrito de $\mathrm{Alexy}^{63}$, las medidas restrictivas de los derechos fundamentales podemos definirlas como aquellas intromisiones vulneradoras prima facie del ámbito de protección de los derechos fundamentales, lo que implica que conforman el supuesto de hecho del derecho fundamental, y que, por este motivo, precisan de justificación conforme a un límite y, asimismo, al principio de proporcionalidad. En dicha noción y, en particular, en cada uno de los tres elementos que la conforman, han de considerarse incluidas las peculiaridades derivadas del reconocimiento de las «violaciones por omisión».

Para formular dicho concepto se ha tomado como punto de partida la contraposición entre el supuesto de hecho del derecho fundamental o vertiente positiva y la justificación o vertiente negativa formulada por Alexy ${ }^{64}$. Los dos factores conformadores de las medidas restrictivas, como son el supuesto de hecho y la necesidad, ante tal cumplimiento, de justificación conforme a los límites a los derechos fundamentales, han sido asimismo manifestados por Peces-Barba ${ }^{65}$, quien mantiene la distinción efectuada por De Otto entre los límites de los derechos y las situaciones no circunscritas en el supuesto de hecho de la norma reguladora de un derecho. Según el citado autor, aquellos casos que no se incluyen

${ }^{61}$ Der Grundrechtseingriff..., op. cit. p. 21 quien, en esta monografía, ofrece una particular aportación sobre este problema planteado con la búsqueda de nuevos criterios. Así, después de analizar la función que la «restricción en los derechos fundamentales» cumple en la dogmática jurídica clásica, estudia tal concepto de restricción bajo «la concepción independiente de intromisión de los derechos fundamentales" ("die eingriffsunabhängige konzeption») en las pp. 26-47.

${ }^{62}$ GOMES CANOTILHO, Direito Constitucional, Coimbra, 6º ed, 2002, p. 448 ha señalado que «se debe hablar de una restricción de derechos cuando se produce una efectiva limitación del ámbito de protección de tales derechos».

63 Vide nota n 12. En el mismo sentido, ECKHOFF, Der Grundrechtseingriff, Köhl, Berlín, Bonn, München, p. 20.

${ }^{64}$ Teoría de los..., op. cit., p. 295; asimismo, dicha contraposición ha sido puesta de relieve por ECKHOFF, Der Grundrechtseingriff..., op. cit., p. 10.

65 Curso de Derechos..., op. cit., pp. 589 y 590. 
en el contenido de un derecho no precisan de justificación de acuerdo con la teoría de los límites. En sentido contrario, resulta necesario efectuar una justificación desde la teoría de los límites cuando la medida estatal se incluye en el supuesto de hecho del derecho afectado. Por ello, a juicio del autor ${ }^{66}$ constituye un paso previo a la justificación conforme a la teoría de los límites la configuración del supuesto de hecho de los derechos fundamentales.

Del concepto expuesto, cabe derivar sus requisitos.

\section{B) Requisitos}

El concepto de «restricción de Derechos Fundamentales» se configura mediante la interrelación de tres elementos, como así han sido distinguidos igualmente por la doctrina alemana ${ }^{67}$ y portuguesa ${ }^{68}$ : en primer lugar, que la actuación estatal incida sobre el ámbito de protección del derecho; en segundo término, que dicha actuación estatal constituya una intromisión eventualmente vulneradora, lo que conforma el supuesto de hecho del derecho fundamental, y, en tercer lugar, que la mencionada intromisión sobre el ámbito de protección del derecho, se justifique, de conformidad con un límite y, en última instancia, con el principio de proporcionalidad. Los mencionados requisitos de las restricciones de los derechos fundamentales, que junto con el cumplimiento de dos presupuestos, como son el relativo al principio de legalidad y el hecho de que persigan fines constitucionalmente legítimos ya fueron expuestos en otro artículo ${ }^{69}$, se recuerdan resumidamente a continuación.

a) El supuesto de hecho de cada derecho fundamental lo conforman el conjunto de actuaciones prohibidas o, lo que constituye la otra cara de la moneda, protegidas "prima facie» por el correspondiente derecho.

Si aplicamos dicha afirmación sobre el ejemplo indicado al inicio del trabajo, podemos afirmar que si llevamos a cabo una intromisión, bien una entrada o

66 PECES-BARBA, Curso de derecho..., op. cit., pp. 589 y 590.

${ }^{67}$ ECKHOFF, Der Grundrechteingriff..., op. cit., pp. 9 y ss y 22 y ss; asimismo, SCHMALZ, Grundrechte..., op. cit., pp. 50 y ss y 63 y ss.

${ }^{68}$ Se señala en el ordenamiento portugués que para afirmar la existencia de una restricción es necesario efectuar un análisis destinado a resolver tres interrogantes: 1) la delimitación del ámbito de protección de la norma. 2) la averiguación del tipo, naturaleza y finalidad de la restricción. 3) el control de la observancia de los límites establecidos por la Constitución de las leyes restrictivas (problema de los límites de límites), Cfr. GOMES CANOTILHO, Direito Constitucional..., op. cit., p. 449.

69 Vide nota $n^{\circ} 2$. 
bien una entrada seguida de un registro (art. 18.2 CE), sobre el ámbito constitucionalmente protegido por dicha norma (art. 18.2 CE), esto es, en un lugar calificable como domicilio ex Constitutione, se cumple el supuesto de hecho de dicha norma de derecho fundamental (art. 18.2 CE). Ello conlleva una consecuencia jurídica como es que se activa el efecto protector del derecho fundamental a la inviolabilidad del domicilio, lo que nos lleva a afirmar que existe un derecho a que prima facie no se intervenga sobre dicho domicilio, esto es, a que dichas actuaciones estén en principio prohibidas. En este sentido, el propio art. 18.2 CE declara «el domicilio es inviolable. Ninguna entrada o registro podrá hacerse en él sin... salvo...».

Así, pues, para que se cumpla dicho supuesto de hecho han de observarse a su vez dos condiciones: de un lado, la actuación de los poderes públicos tiene que incidir sobre el ámbito de protección del derecho y, de otro, dicho acto ha de calificarse como una intromisión.

a') En cuanto al ámbito de protección, su identificación viene determinada, a juicio de Schmalz ${ }^{70}$, por la inclusión de una serie de conceptos, denominados "conceptos guía» ("Leitbegriff»), que se corresponden en nuestra Ley Fundamental, entre otros, con la vida, integridad física y moral (art. 15), honor, intimidad personal y familiar, imagen (art. 18.1), domicilio (art. 18.2) y comunicaciones (art. 18.3). Asimismo la salvaguarda de tales esferas de libertad se hace patente en nuestra Constitución conforme a la consagración constitucional de diferentes expresiones o formulaciones ${ }^{71}$, tales como el reconocimiento de «derechos", de reunión pacífica (art. 21) o de asociación (art. 22), a participar en asuntos públicos (art. 23), a la educación (art. 27), de petición (art. 29), de «libertades», como la libertad de residencia (art. 19), libertad de expresión (art. 20), de "garantías», como la aplicable al derecho al honor, intimidad personal, familiar e imagen (art. 18.1) o la relativa al secreto de las comunicaciones (art. 18.3) y de la «inviolabilidad» referida al ámbito domiciliario (art. 18.2). Ahora bien, como se ha puesto de relieve ${ }^{72}$, a través de cada uno de estos derechos, se puede amparar un ámbito de libertad en sentido negativo, frente a una vulneración del Estado, así como en sentido positivo, frente a una violación por omisión de los poderes públicos en cuanto que incumplen con el deber de garantizar dicha esfera de protección. Este segundo supuesto aconteció, por ejem-

${ }^{70}$ Grundrechte..., op. cit., pp. 32 y 51.

71 SCHMALZ, Grundrechte..., op. cit., p. 51.

72 SCHMALZ, Grundrechte..., op. cit., p. 51 pone como ejemplo el art. 4.I referido a la inviolabilidad de la libertad de creencias o el art. 5 I 1 que alude al derecho a expresar libremente una opinión sin trabas como ejercicio de libertad negativas. 
plo, cuando se estimó la violación de la vida privada en el domicilio (art. 8 $\mathrm{CEDH}$ ), derivada de la omisión de los poderes públicos españoles del deber de garantizar dicho derecho, en la STEDH «Asunto López Ostra»"

b') En relación con las intromisiones, intervenciones o injerencias, pueden definirse como el conjunto de actuaciones protegidas o prohibidas por el correspondiente derecho fundamental, lo cual, a juicio de Eckhoff ${ }^{74}$, supone el cumplimiento de dos condiciones.

a") En primer lugar, han de constituir «violaciones» ("Beeinträchtigungen») que afectan exactamente al correspondiente ámbito de protección, motivo por el cual, constituyen cualificadas violaciones de dicha esfera. En este sentido, Schmalz ${ }^{75}$ ha manifestado que la afección debe ocasionar un perjuicio tal que dificulte o impida el ejercicio del derecho fundamental, lo que significa que debe tratarse de una vulneración efectivamente ocasionada y no absolutamente insignificante.

b“') En segundo lugar, satisfecho el señalado requisito, han de tratarse únicamente de aquellas vulneraciones calificables "per se» como intromisiones, lo que reclama una determinada relación de causalidad entre la actuación y el efecto vulnerador de la esfera protegida. De la búsqueda de tales requisitos se está ocupando la doctrina alemana y, en este sentido, ha apuntado Eckhoff ${ }^{76}$, que para calificar una actuación como intromisión de un derecho fundamental, habría que preguntarse si, por las consecuencias de las referidas medidas sobre el ámbito de libertad de su titular, se justifica que adquiera tal condición. De conformidad con tal criterio, puede plantearse, junto con las intromisiones clásicas de carácter intencional, jurídico y directo, la excepcional incorporación de las intromisiones involuntarias, fácticas, así aquellas intromisiones que se ocasionan de forma mediata.

Así, de acuerdo con la concepción clásica de "Eingriff» las intromisiones deben ser finales ("Finalität»), en el sentido de que, a través de ellas, la vulneración constituye una consecuencia voluntaria ("beabsichtigte Nebenfolge»), pues logra el resultado vulnerador pretendido por el autor. Además, si se toman en cuenta las nuevas formas de violación, podrían admitirse aquellas intromisiones que oca-

73 Vide nota $\mathrm{n}^{\circ} 45$

${ }^{74}$ Der Grundrechteingriff..., op. cit., pp. 19 y 20.

75 En este sentido, el citado autor ha definido «intromisión" ("Eingriff») "como aquella violación efectivamente ocasionada y no absolutamente insignificante de los bienes protegidos a través de un acto de autoridad ("Hoheitsakt») de manera que el bien jurídico protegido por el derecho fundamental sufre una influencia perjudicial porque dificulta o impide el ejercicio del derecho fundamental en el futuro inmediato, Grundrechte..., op. cit., p. 52.

${ }^{76}$ ECKHOFF, Der Grundrechtseingriff..., op. cit., p. 237. 
sionan una violación de forma inintencionada («unbeabsichtigte Nebenfolge»), como ha hecho la doctrina alemana ${ }^{77}$ y la jurisprudencia del $\mathrm{BVerwG}^{78}$.

Asimismo, conforme a la noción tradicional de «restricción de Derechos Fundamentales», las intromisiones o injerencias tienen que revestir una forma jurídica calificable como límite (Schranken). A este respecto, resulta relevante la clasificación formulada por Peces-Barba ${ }^{79}$ sobre los límites a los derechos fundamentales y, en concreto, respecto de los límites del subsistema de derechos fundamentales, los cuales son límites propios y exclusivos de los derechos fundamentales y ostentan una naturaleza formal, puesto que revisten un carácter habilitador o competencial. En particular, se refieren a: A) límites formulados por el legislador, como son: a) las reservas legales expresas. Es el caso del derecho de acceso a las funciones y cargos públicos con los requisitos que señalen las leyes (art. 23.2 CE); b) las reservas legales cualificadas. Son frecuentes, como el caso del delito flagrante respecto de la inviolabilidad del domicilio (art. 18.2), de la consagración del derecho fundamental a la libertad ideológica, religiosa y de culto con la única limitación que el mantenimiento del orden público protegido por la ley (art. 16.1 CE); la limitación legal del uso de la informática para garantizar únicamente los derechos fundamentales al honor e intimidad personal y familiar y pleno ejercicio de los derechos (art. 18.4 CE), art. 19. IICE; art. 28.1 II CE, entre otros. Y, junto con ellos, B) los límites formulados por el órgano jurisdiccional. Es el supuesto, del derecho a la inviolabilidad del domicilio (art. 18.2 CE), del derecho al secreto de las comunicaciones (art. 18.3 CE); la libertad de expresión a través del secuestro de publicaciones (art. 20.5 CE) y la disolución de asociaciones (art. 22.4 CE). En consecuencia, en virtud de alguno de tales límites tiene que efectuarse la intromisión.

Ahora bien, de acuerdo con la nueva concepción cabe plantearse en qué medida las violaciones fácticas ("faktische») revisten el carácter de intromisión. Pues, bien, la admisión de las mencionadas violaciones como intromisiones ha

77 PIEROTH;SCHLINK, Grundrechte. Staatsrecht II..., op. cit., p. 65; BLECKMANN, Staatsrechts II. Die..., op. cit., p. 339; SCHMALZ, Grundrechte..., op. cit., p. 55.

78 Se refiere a la BVerwGE 87, 37 (42). Este ejemplo, relativo a una intromisión en la vida e integridad corporal la muerte de un ciudadano alcanzado por un disparo involuntario de un agente de la policía, ha sido tomado de SCHMALZ, Grundrechte..., op. cit., p. 55. Asimismo, BVewGE 90, 112 (120), cit. en SCHAMLZ, Grundrechte..., op. cit., p. 56, referida al efecto previsible pero no pretendido consistente en la violación del derecho al libre desarrollo de la personalidad de los ciudadanos ocasionada por el considerable aumento del nivel del ruido, debido a la construcción de una nueva calle.

79 Curso de Derechos..., op. cit., p. 590. 
sido defendida por Bleckmann ${ }^{80}$ quien afirma que pueden reconocerse como restricción aquellas que se han efectuado "de hecho", esto es, o bien sin incluirse en una orden judicial ( $B$ Befehl») o sin que constituya un supuesto de coacción administrativa ( $Z$ Zwang»); y, asimismo, por Eckhoff ${ }^{81}$ que ha considerado igualmente las intromisiones fácticas, siempre que resulten suficientemente gravosas.

Finalmente, junto con las intromisiones ocasionadas directamente por los poderes públicos ("Unmittelbare»), resulta realmente controvertida la admisión, como intromisiones de los derechos fundamentales, de aquellas que ocasionan una vulneración de forma mediata ("Mittelbare») imputables al Estado, al no reconocer la vigencia de los derechos fundamentales entre particulares no vinculados jurídicamente o entre los que concurre dicha relación. Un sector de la doctrina alemana ${ }^{82}$ parte del reconocimiento de las violaciones mediatas como intromisiones. Igualmente se ha reconocido con carácter general por el BVerfG y el BVerwG ${ }^{83}$. Sin embargo, Eckhoff ${ }^{84}$ ha puntualizado que tal reconocimiento tiene que reducirse al mínimo. Para ello, se han formulado algunos criterios. De un lado $^{85}$ se ha propuesto solucionar el problema referido al reconocimiento de las violaciones por «omisión», desde la estructura de la dogmática de los derechos fundamentales como derechos de defensa. Otro criterio utilizado ${ }^{86}$, que resulta aceptable, consiste en analizar la relación de causalidad existente entre el resultado vulnerador ocasionado y la actuación que lo ha producido. En particular, se señala que tras identificar la hipotética actuación estatal debe comprobarse si hubiera resultado apropiada su realización para evitar el supuesto resultado.

80 Staatsrecht II. Die Grundrechte..., op. cit., p. 337.

81 Der Grundrechtseingriff..., op. cit., p. 278.

82 PIEROTH; SCHLINK, Grundrechte. Staatsrecht II..., op. cit., p. 65 ; BLECKMANN, Staatsrechts II. Die Grundrechte..., op. cit., p. 339; SCHMALZ, Grundrechte..., op. cit., p. 55.

83 Sin embargo el cumplimiento de tales requisitos no es absolutamente imprescindible puesto que el Tribunal Federal Administrativo alemán así como el Tribunal Constitucional Federal Alemán han admitido en alguna ocasión que acciones estatales que sorprenden de forma efectiva y mediata al titular del derecho fundamental en cuestión puede significar una intromisión del derecho fundamental. BVerWGE 87, 37 [42] y BVerfGE 46, 120 [137] cit. en SCHMALZ, Grundrechte..., op. cit., p. 55. En particular, se pone ejemplo de que una persona alcanzada a través del efecto secundario e involuntario de un disparo policial constituye una «intromisión» en la vida e integridad corporal de tal sujeto.

${ }^{84}$ Grundrechtseingriff..., op. cit., pp. 279.

${ }^{85}$ LÜBBE-WOLFF, Eingriffabwehrrechte cit. en ECKHOFF, Der Grundrechtseingriff..., op. cit., p. 282.

${ }^{86}$ ECKHOFF, Der Grundrechtseingriff..., op. cit., p. 278-280. 
Por su parte, nuestro TC ha considerado como intromisión, en diversos derechos fundamentales del trabajador, la resolución judicial (recurrida en amparo) en la que se estima procedente el despido aun cuando se llevó a cabo vulnerando distintos derechos fundamentales del trabajador, como son los derechos contemplados en el art. 18.1 $\mathrm{CE}^{87}$ o en la libertad de expresión ${ }^{88}$.

b) Una vez que la actuación de los poderes públicos forma parte del contenido del derecho, tiene que cumplirse un tercer requisito para que dicha intromisión, que en principio, ha vulnerado el ámbito de protección de un derecho fundamental, resulte finalmente conforme a la Constitución y, en consecuencia, pueda calificarse como una medida restrictiva de derechos fundamentales. Dicha condición consiste en que dicha actuación revista la forma de un límite constitucional y, en última instancia, cumpla con el principio de proporcionalidad.

Si aplicamos dicha afirmación sobre el ejemplo indicado al inicio del trabajo, podemos afirmar que una vez que se práctica una entrada y registro en un domicilio ex Constitutione, se activa el efecto protector del derecho fundamental a la inviolabilidad del domicilio, lo que nos lleva a afirmar que existe un derecho a que prima facie no se intervenga sobre dicho domicilio, esto es, a que dichas actuaciones estén en principio prohibidas. En este sentido, el propio art. 18.2 CE declara «el domicilio es inviolable. Ninguna entrada o registro podrá hacerse en él sin... salvo...». Es entonces cuando surge la necesidad de justificación en virtud de un límite, Así, el propio art. 18.2 CE indica, «...podrá hacerse en él sin consentimiento del titular o resolución judicial, salvo en caso de flagrante delito». Ello significa que si la entrada o registro se ha llevado a cabo con el consentimiento del titular o en virtud de alguno de los dos límites indicados, de un lado, la resolución judicial o, de otro, el supuesto del delito flagrante, sin perjuicio de que asimismo sea respetuosa con el principio de proporcionalidad el cual, como veremos en el epígrafe II de este trabajo se encuentra implícitamente reconocido en el art. 18.2 CE), dicha entrada o registro domiciliario será una medida constitucionalmente legítima y, en consecuencia, podrá considerarse como una medida restrictiva del derecho fundamental a la inviolabilidad del domicilio. Si no estuviese justificada ex Constitutione, se trataría de una actuación definitivamente vulneradora del derecho fundamental a la inviolabilidad del domicilio.

El mencionado principio de proporcionalidad, en su dimensión clásica, y comprensivo de los principios, de adecuación, necesidad y proporcionalidad en

87 SSTC 170/1987, de 30 de octubre; 99/1994, de 11 de abril (FJ $7^{\circ}$ ).

88 SSTC 186/1996, de 25 de noviembre (FJ 3); 151/2004, de 20 de septiembre; 198/2004, de 15 de noviembre; 181/2006, de 19 de junio; 56/2008, de 14 de abril. 
sentido estricto, ha sido expuesto por la doctrina ${ }^{89}$ y plenamente configurado por la jurisprudencia de nuestro Tribunal Constituciona ${ }^{90}$, que ha de interpretarse de conformidad con la dictada por el TEDH. Ahora bien, no cabe la aplicación del principio de proporcionalidad, configurado en el mencionado sentido clásico, sobre los supuestos de intromisiones involuntarias, fácticas, mediatas. Por el contrario, según Bockenförde ${ }^{91}$, el criterio de proporcionalidad, que se aplica en los novedosos supuestos de intromisión señalados, consiste en una proporcionalidadadecuación que no actúa, tanto en el caso concreto, cuanto respecto al contenido de la regulación. En tal disposición legislativa se debe lograr el adecuado equilibrio entre los contradictorios principios normativos en juego. El principio de proporcionalidad, en tales casos, incide fundamentalmente en la actuación del legislador, quien delimita en este sentido el campo de actuación de los aplicadores del derecho. Y, ello, sin perjuicio de que también se respete en el caso concreto, mediante la aplicación del juicio de ponderación entre la omisión del poder público y el fin que persigue con su conducta. A este respecto, la jurisprudencia de nuestro $\mathrm{TC}^{92}$,

89 Entre otros, GONZALEZ-CUÉLLAR SERRANO, Proporcionalidad y derechos fundamentales, Madrid, 1990, p. 53.

90 Desde la STC 207/1996, de 16 de diciembre (FJ $4^{\circ}$ ) donde el TC adopta plenamente los requisitos derivados del principio de proporcionalidad, el TC ha consolidado dicha jurisprudencia con las SSTC 37/1998, de 17 de febrero (FJ 8); 166/1999, de 27 de septiembre (FJ 5०); 292/2000, de 30 de noviembre (FJ 16 $)$, 202/2001, de 15 de octubre (FJ 2 ${ }^{\circ}$ ), 206/2007, de 24 de septiembre $\left(\mathrm{FJ} 5^{\circ}\right.$ y $\left.6^{\circ}\right)$.

${ }_{91}$ Sin embargo, el principio de proporcionalidad también tiene que actuar ante las violaciones por omisión. También el carácter de principio de la norma de derecho fundamental tiene que tomarse en cuenta en la dimensión objetiva de derechos fundamentales. En este sentido, BOCKENFÖRDE, Escritos sobre derechos..., op. cit., pp. 124, 125, 126 y 130.

92 En particular, la STC 99/1994, de 11 de abril, en la que se considera como intromisión la actuación del empresario, afirma que, conforme al juicio de necesidad, debe acreditarse que no es posible alcanzar de otra forma el legítimo objetivo perseguido, porque no existe medio razonable para lograr una adecuación entre el interés del trabajador y el de la organización en la que se integra. Asimismo, en la STC 186/1996, de 25 de noviembre, se efectúa un doble juicio de necesidad, respecto del empleador y en relación con la sentencia que resolvió el conflicto. Señala, en cuanto al empleador, que la modulación del contrato que efectuó el empresario sólo debe realizarse, dada la posición privilegiada que los derechos fundamentales ocupan en nuestro ordenamiento, en la medida estrictamente indispensable para el adecuado desenvolvimiento de la actividad productiva. Respecto a la sentencia, pone de relieve que tiene que preservar el necesario equilibrio entre la obligación del trabajador y el ámbito modulado por el contrato. En el mismo sentido, STC 56/2008, 14 de abril (FJ 6), en relación con la libertad de expresión, en cuyo FJ $7^{\circ}$ señala que, desde la perspectiva de la prevalencia de los derechos fundamentales, su limitación solo puede derivar, bien del hecho de que la propia naturaleza del trabajo contratado implique la restricción del derecho, bien de una acreditada necesidad o interés empresarial, sin que sea suficiente su mera invocación para sacrificar el derecho fundamental del trabajador. 
ha ido aplicando el principio de proporcionalidad a actuaciones vulneradoras del Estado por «omisión» y, en particular, el principio de necesidad. Dicha jurisprudencia tendrá que interpretarse de conformidad con la dictada por el TEDH que, en particular, y en lo que respecta a la aplicación del juicio de proporcionalidad en el caso de injerencias ocasionadas entre particulares se ha pronunciado, en relación con diferentes derechos: así, por ejemplo, respecto al derecho a la vida privada y al domicilio (art. $8 \mathrm{CEDH})^{93}$; asimismo, ha analizado, acerca de la violación del derecho a la libertad de expresión (art. $10 \mathrm{CEDH})^{94}$, si la injerencia consistente en una sanción impuesta por una empresa a un trabajador (y demandante de amparo), consistente en un despido por manifestaciones consideradas como ofensivas contra la empresa, era proporcionada al fin legítimo perseguido, esto es, la protección de la reputación de las personas aludidas en las mencionadas declaraciones del demandante.

\section{FUNDAMENTO CONSTITUCIONAL}

Efectuadas tales afirmaciones, cabe justificar el engarce constitucional de la «restricción de los Derechos Fundamentales». La mencionada figura jurídica no se proclama expresamente en ningún precepto constitucional. Sin embargo, puede fundamentarse su implícita proclamación en cada uno de los artículos de nuestra Carta Magna donde se regulan los derechos fundamentales y sus límites, de conformidad con la distinción entre reglas y principios ${ }^{95} \mathrm{y}$, en particular, con la tesis de la «doble estructura de la Norma de Derecho Fundamental» formulada por Alexy ${ }^{96}$. Por ello, a continuación se expondrán las razones por las que

${ }^{93}$ Vide nota ${ }^{\circ} 45$ y 71. STEDH «Asunto López Ostra» de 9 de diciembre de 1994 ( $\left.\mathrm{n}^{\circ} 48\right)$ en la que el TEDH, tras un ponderativo juicio de los intereses en conflicto, apreció, ilegítima, la intromisión en los derechos contemplados en el art. 8 porque entendió que los demandantes resultaron afectados ante la injusta preeminencia otorgada al bienestar económico en detrimento de la protección medioambiental. En particular, el citado Tribunal consideró que el Estado español no actuó en favor de la consecución del equilibro entre los intereses económicos de una de las partes, el Municipio de Lorca, representados por la empresa causante del daño y el efectivo disfrute por parte de la demandante de su derecho al respeto de su domicilio y vida privada y familiar.

94 STEDH de 29 de febrero del 2000 (n ${ }^{\circ}$ 44-50).

95 En cuanto a la relación entre la teoría de las restricciones y la teoría de los principios, vide BOROWSKI, La restricción de los derechos fundamentales», REDC, $\mathrm{n}^{\circ} 59$, mayo-agosto 2000, pp. 39-44.

96 En particular, son denominadas por el autor germano como «normas iusfundamentales con doble carácter» y, concretamente, se les otorga naturaleza de «regla» así como de "principio». Teoría de los..., op. cit., pp. 135-138. 
cabe afirmar que todas aquellas actuaciones estatales que inciden sobre derechos fundamentales, tales como, entre otras, la detención (art. 17. CE), la intervención de las comunicaciones (art. 18.3 CE) o la entrada y el registro domiciliario (art. 18.2 CE) deberían ser calificadas medidas restrictivas de los derechos fundamentales sobre los que inciden, porque así se infiere de la naturaleza de los preceptos constitucionales donde se proclaman.

En efecto, para llegar a tal conclusión, se ha utilizado la teoría del «doble carácter de la Norma de Derecho Fundamental» porque, tanto el punto de partida de su teoría respecto de los límites a los derechos fundamentales, la teoría externa, cuanto las consecuencias derivadas de ella, la aplicación del principio de proporcionalidad, son acordes con la jurisprudencia que el Tribunal Constitucional español ha vertido en torno a los límites a los derechos fundamentales. Veamos, pues, la posición de Alexy y su correspondencia con la jurisprudencia de nuestro Tribunal Constitucional, así como las consecuencias derivadas de su aplicación a las normas de los derechos fundamentales contenidas en nuestra Constitución.

\section{La teoría de la "doble estructura de la Norma de Derecho Fundamental» de Alexy y la jurisprudencia del TC}

Señala Alexy ${ }^{97}$ que, según la teoría de los Derechos Fundamentales, la más importante distinción teórico-estructural que puede formularse respecto de la «Norma de Derecho Fundamental» con el propósito de alcanzar una adecuada teoría de los límites a los derechos fundamentales es la que se efectúa entre «reglas» $\mathrm{y}$ "principios». Con carácter previo a la exposición de la tesis formulada por Alexy respecto de la cuestión objeto de estudio, conviene explicar con más detalle por qué se ha adoptado tal postura, en este trabajo.

La razón reside en que, en cuanto a los límites a los derechos fundamentales, Alexy parte de la "teoría externa», que se corresponde con la posición que, a este respecto, adoptó tempranamente nuestro Tribunal Constitucional, denominada «teoría de los límites inmanentes» y que fue secundada por un sector de la doctrina constitucionalista. Tomadas tales teorías como punto de partida, en ambos casos se ha llegado a la conclusión de que las restricciones que los límites efectúan sobre los derechos fundamentales, en principio vulneradoras de tales derechos, necesitan justificarse en el principio de proporcionalidad para que resulten conformes a la Constitución.

97 Teoría de los Derechos..., op. cit., p. 81. 
Ha manifestado Alexy que, conforme a la "teoría externa»" ${ }^{98}$, cabe distinguir el derecho, de un lado, y sus límites o restricciones, de otro, entre los que opera una relación especial, denominada de limitación o restricción, tan sólo cuando concurre una necesidad, externa al derecho, de compatibilizarlos con otros derechos individuales y bienes colectivos. Por ello, a diferencia de la teoría interna ${ }^{99}$ cuyo ámbito de protección es invariable, conforme a la teoría externa, el problema reside, no tanto en cuál es el contenido del derecho, ante la variación que puede experimentar, cuanto si tal ámbito de protección debe ser o no limitado. En este sentido, en la medida en que se admite tal limitación, disminuye el contenido del derecho fundamental, lo que permite distinguir entre el «derecho en sí» o «posiciones prima facie» y el «derecho limitado» o «posiciones definitivas». A partir de la teoría externa y, en consecuencia, de la distinción entre "derecho en sí» y el «derecho limitado», Alexy sostiene que concurre tal necesidad de restricción, esto es, pueden limitarse derechos fundamentales conforme a la Constitución, en la medida en que tales restricciones cumplan con los requisitos derivados del principio de proporcionalidad. Tal exigencia se deriva, a su juicio, del carácter de "principio» que, junto con la naturaleza de «regla», ostenta toda norma de derecho fundamental pues, tal y como se explicará más adelante, constituye, junto con una orden de prohibición, un mandato de ponderación.

Y en lo que se refiere a la jurisprudencia de nuestro Tribunal Constitucional, el citado Tribunal admitió, sobre la base de la limitación general de los derechos fundamentales, y, a partir de la adopción de la denominada «teoría de los límites inmanentes» que se corresponde con la teoría externa, la concurrencia de una necesidad de compatibilizar los derechos fundamentales con otros derechos individuales y bienes colectivos. Tal posición fue secundada por un sector de la

${ }^{98}$ La distinción entre la teoría externa y la teoría interna ha sido puesta de relieve por ECKHOFF, Der Grundrechteingriff..., op. cit., pp. 12-13; ALEXY, Teoría de los..., op. cit., pp. 268 y 269; HÄBERLE, La Libertad Fundamental en el Estado Constitucional, Perú, 1997, pp. 114-116. En particular, señala ALEXY, Teoría de los..., op. cit., p. 268, 269 y 272, que aunque es cierto que los derechos se formulan esencialmente como derechos limitados, conforme a la teoría externa pueden imaginarse derechos sin límites puesto que tal limitación tiene lugar en aquellos casos en que concurra una necesidad externa al derecho de limitarlos.

99 De acuerdo con la teoría interna, postulada por HÄBERLE, La Libertad Fundamental..., op. cit., pp. 114-116, los límites a los derechos fundamentales son internos, existen «desde el inicio». Los derechos fundamentales se garantizan tan sólo en el ámbito de sus límites inmanentes y, por ello, no resultan privados de lo que les corresponde «de por sí». Por esta razón, según ECKHOFF, Der Grundrechteingriff..., op. cit., pp. 14 y 15, conforme a la teoría interna, la intromisión en el ámbito de protección del derecho fundamental, no precisaría justificación, sino que tendría que ser necesariamente constitucional. 
doctrina constitucionalista ${ }^{100}$ el cual, junto con el reconocimiento de los límites intrínsecos, admitió los límites extrínsecos. En particular, tales límites extrínsecos se distinguen entre aquellos expresamente consagrados en nuestra Constitución y los derivados mediatamente de la señalada Ley Fundamental, en la medida en que concurra la necesidad de conciliarlos con otros derechos fundamentales y bienes constitucionalmente legítimos. Tal necesidad de justificación de los límites se fue transformando progresivamente por el Tribunal Constitucional en los requisitos derivados del principio de proporcionalidad, de manera que, en la actualidad, nuestro más Alto Tribunal justifica las limitaciones a los derechos fundamentales a través del mencionado principio ${ }^{101}$. Puesto que, como se acaba de señalar, la teoría externa y las consecuencias derivadas de ella son las que mejor se adaptan a la jurisprudencia de nuestro Tribunal Constitucional, conviene ahora que sea expuesta con mayor detalle para extraer de ella nuevas consecuencias.

Se ha señalado que conforme a la teoría externa, según la cual, de acuerdo a la limitación general de los derechos fundamentales no resulta posible limitar en principio derechos fundamentales salvo que se justifique, cabe diferenciar entre "posiciones prima facie» que prohíben eventualmente todas las actuaciones sobre derechos fundamentales y "posiciones definitivas» que prohíben permanentemente tan sólo aquellas que no se justifican. Tal distinción es posible, como sostiene Alexy, ante el reconocimiento de que las normas de derecho fundamental ostentan una doble estructura, como «regla», de un lado, y como "principio», de otro. Sin entrar en la discusión en torno a la diferencia entre «reglas» y "principios», se explica a continuación qué significa cada uno de los señalados componentes del ordenamiento jurídico para el citado autor alemán que, como no positivista, adopta una «teoría fuerte» en cuanto a la distinción entre ambos elementos.

Alexy, al igual que otros autores como Dworkin ${ }^{102}$, concibe el ordenamiento jurídico, no sólo como reglas, como afirmaría un positivista como Kelsen, sino

100 En nuestro ordenamiento, AGUIAR, «Los límites de los Derechos Fundamentales», RCEC, enero-abril 1993, nº 18-19, p. 13; FERNÁNDEZ SEGADO, «La dogmática de...», op. cit., p. 102; JIMÉNEZ CAMPO, «El legislador de los Derechos Fundamentales». Estudios de Derecho Público. Homenaje a Ignacio de Otto. Oviedo, 1993, pp. 481-484.

${ }_{101}$ Fue fundamentalmente a partir de la STC 207/1996, de 16 de diciembre (F J 4º) donde el TC adopta plenamente los requisitos derivados del principio de proporcionalidad.

102 Sobre la relación entre reglas y principios que acuñó DWORKIN, Los derechos en serio, Barcelona, $2^{a}$ ed., 1989, pp. 61-145 y secundó Alexy, puede resultar apropiada la lectura de las páginas correspondientes de GARCÍA FIGUEROA, Principios y positivismo jurídico, Madrid, 1998, pp. 163-216. 
también como principios ${ }^{103}$, sin perjuicio de que añada un tercer elemento como es la teoría de la argumentación jurídica. Asimismo, Alexy, en la línea que sostiene Dworkin cuya teoría completa, mantiene ${ }^{104}$ que la distinción entre «reglas» y "principios», no sólo reside en una cuestión de grado, en cuyo caso se sustentaría una postura débil ${ }^{105}$, sino que además se diferencian cualitativamente. Por este doble motivo, mantienen ${ }^{106}$ una distinción entre reglas y principios en sentido fuerte. En particular, Alexy, señala que, conforme al carácter de regla ${ }^{107}$, la norma ordena la prohibición de todas aquellas actuaciones que cumplan el supuesto de hecho del derecho fundamental, esto es, de cualquier intromisión que incida sobre el objeto de protección de los mencionados derechos. Ahora bien, si tan sólo se reconociese que la norma de derecho fundamental disfruta de un carácter de regla, se admitiría que los derechos fundamentales son absolutos, por lo que estaría prohibida cualquier intromisión sobre tales posiciones.

Por el contrario, conforme a la teoría externa se afirma la limitabilidad de los derechos fundamentales mediante la atribución, a la mencionada orden de prohibición de toda injerencia, de un carácter prima facie ${ }^{108}$, lo que se pone de manifiesto con la introducción, junto con la proclamación del derecho fundamental, de una "cláusula restrictiva» que recoge la posibilidad de que determinados derechos y bienes, que denomina "principios opuestos», que deben tener rango constitucional, tengan preferencia sobre los derechos fundamentales ${ }^{109}$. Señala Alexy ${ }^{110}$ que la cláusula restrictiva reviste carácter de "principio». En este sentido cabe efectuar dos afirmaciones.

De un lado, al constituir el «principio» una excepción a la regla se pone de relieve, tal y como ha manifestado Prieto Sanchís ${ }^{111}$, que la «regla» no se aplica o

${ }^{103}$ Los principios constituyen elementos que configuran el ordenamiento jurídico. Pero aunque constituye un elemento necesario no resulta suficiente para que, ante un caso jurídico, pueda alcanzarse una única respuesta correcta. Alexy considera, dado que mantiene un teoría débil sobre los principios, que para llegar a un modelo completo del sistema jurídico tiene que añadirse un tercer nivel como es una teoría de la argumentación jurídica orientada de acuerdo con el concepto de razón práctica. En este sentido, ALEXY, «Sistema jurídico, principios jurídicos y razón práctica», Derecho y Razón Práctica, México, 1993, pp. 19-23.

104 ALEXY, «Sistema jurídico, principios...», op. cit., p. 11.

105 PRIETO SANCHÍS, Sobre principios y normas. Problemas del razonamiento jurídico. Madrid, 1992, p. 55

106 ALEXY, «Sistema jurídico, principios...», op. cit., p. 11.

107 ALEXY, Teoría de los..., op. cit., p. 87 y 137.

108 Op. cit., p. 136.

109 Op. cit., pp. 136 y 137.

110 Op. cit., p. 86.

111 Sobre principios y..., op. cit., pp. 38 y 39. 
no se aplica en todo caso dependiendo de que se cumpla el supuesto de hecho, puesto que si los principios pueden exceptuar a las reglas y no cabe enumerar las excepciones a los principios y tampoco los supuestos de aplicación, tampoco se podrán saber los casos de excepción a las reglas. Como el mismo autor ${ }^{112}$ señala, ello supone, en los casos en que se adopta una postura estricta o fuerte, como defiende Alexy, un cambio de acento de la estructura a la función, esto es, desde un punto de vista estructural la distinción entre reglas y principios es clara pero funcionalmente tal diferencia se diluye.

De otro, puede señalarse que tiene naturaleza de "principio» entendido en un sentido débil ${ }^{113}$. Conforme a tal postura, el «principio» constituye una norma que ordena que algo sea realizado en la mayor medida posible dentro de las posibilidades reales y jurídicas. En primer lugar, se consideran reales, porque resultan necesarias y adecuadas y, en segundo término, se califican como jurídicas, en la medida en que se adecuen al principio de proporcionalidad en sentido estricto. Así, pues, el principio de proporcionalidad, que se divide en los tres subprincipios señalados, de adecuación, necesidad y proporcionalidad en sentido estricto, se contiene en cada norma de derecho fundamental porque se deriva de su esencia ${ }^{114}$, esto es, constituye un límite inmanente de cada uno de estos derechos. Con el juicio de ponderación que se introduce a través del carácter de principio que la cláusula restrictiva reviste, se pretende alcanzar una solución óptima y es por ello por lo que señala el autor ${ }^{115}$ que los principios constituyen «mandatos de optimización».

Si cada norma de derecho fundamental reviste la doble naturaleza mencionada con las consecuencias que, como se ha señalado, ello conlleva, puede concluirse que el conjunto de actuaciones que inciden sobre un determinado derecho fundamental a las que se les aplica ambos mandatos, de prohibición y de optimización (derivados respectivamente del carácter de regla, en el sentido fuerte, y de principio que ostenta la norma de derecho fundamental), aun

112 PRIETO SANCHÍS, Sobre principios y..., op. cit., p. 52.

113 A diferencia de Alexy, Dworkin mantiene una postura fuerte de principios conforme a la cual resulta identificables los principios y expresables todas las relaciones de prioridad abstractas y concretas entre ellos, lo que permite determinar unívocamente la solución correcta en cada caso que se plantee. Frente a esta postura, Alexy, mantiene una teoría débil de los principios como mandatos de optimización, lo que le conduce a la ley de la ponderación. Tal ley de ponderación, a juicio del citado autor, no formula otra cosa que el principio de proporcionalidad en sentido estricto. ALEXY, «Sistema jurídico, principios...», op. cit., pp. 15-18.

${ }^{114}$ En este sentido, BVerfGE 19, 342 [348 y ss]; 65, 1 [44], cit. ALEXY, Teoría de los..., op. cit., p. 112.

115 Op. cit., p. 86. 
cuando cumplen el supuesto de hecho del derecho fundamental y, por tanto, en principio, resultasen prohibidas, serán en última instancia constitucionalmente legítimas, si respetan el principio de proporcionalidad. En consecuencia, tal y como se deriva de cada uno de los preceptos donde se proclama cada derecho fundamental y sus límites, aquellas medidas que cumplen con el mandato de prohibición porque satisfacen el supuesto de hecho del correspondiente derecho fundamental y, además, resultan conformes al principio de proporcionalidad, constituyen medidas constitucionalmente legítimas y, por ello, restrictivas o limitativas de derechos fundamentales. Por las mismas razones señaladas, y, a modo de ejemplo, la intervención de las comunicaciones o la entrada y el registro domiciliario en particular, como cualesquiera otras medidas que inciden sobre derechos fundamentales, constituyen restricciones o limitaciones del derecho fundamental al secreto de las comunicaciones o a la inviolabilidad del domicilio, porque así se deriva de los artículos 18.3 y 18.2 de nuestra Constitución, respectivamente, tal y como se explica a continuación.

\section{La implícita proclamación en cada una de las «Normas de Derecho Fundamental»}

La extensión de la teoría de Alexy sobre el doble carácter de las normas de derecho fundamental, como regla y principio en el sentido señalado, a cada una de las normas contenidas en los preceptos 14 a 29 de nuestra Constitución, donde se proclama el correspondiente derecho fundamental y sus límites, permite afirmar que las actuaciones estatales calificables como restricciones de derechos fundamentales se proclaman indirectamente en los mencionados preceptos constitucionales.

Conviene partir de la identificación de la norma con carácter de regla y de norma con naturaleza de principio que se contienen en cada uno de los preceptos constitucionales donde se proclaman los derechos fundamentales y sus límites. En este sentido, tienen carácter de «regla», entre otros casos, las normas siguientes: «se garantiza la libertad ideológica, religiosa y de culto de los individuos y las comunidades» (art. 16.1 CE); «toda persona tiene derecho a la libertad y a la seguridad» (art. 17.1 CE); «el domicilio es inviolable» (art. 18.2 CE); «se garantiza el secreto de las comunicaciones y, en especial, de las postales, telegráficas y telefónicas» (art. 18.3 CE); el reconocimiento y protección de los derechos contemplados en las letras a) b) c) d) del artículo 20 de nuestra Constitución (art. 20.1 CE). Y de principio, entre otras, las normas que se exponen a continuación: «.. sin más limitación, en sus manifestaciones, que la necesaria para el 
mantenimiento del orden público protegido por la ley» (art. 16.1 CE); «Nadie puede ser privado de su libertad, sino con la observación de lo establecido en este artículo y en los casos y en la forma previstos en la ley» (art. 17.1 CE); «Ninguna entrada o registro podrá hacerse en él sin consentimiento del titular o resolución judicial, salvo en caso de flagrante delito" (art. 18.2 CE); "salvo resolución judicial» (art. 18.3 CE); y los casos previstos en los números $3^{\circ}, 4^{\circ}$ y $5^{\circ}$ del artículo 20.

Con la proclamación de cada uno de los mencionados derechos fundamentales, se prohíbe la violación de tales derechos, ya que caen bajo el supuesto de hecho del derecho fundamental. A continuación, se pone de manifiesto el carácter eventual de la señalada prohibición, porque incluye una cláusula restrictiva donde se admite la limitación del derecho, pues permite la realización de intromisiones, como aquellas necesarias para mantener el orden público (art. 16.1 $\mathrm{CE})$, la «detención» (art. 17.2 CE), «la entrada y registro» (art. 18.2 CE), «la intervención de las comunicaciones» (art. 18.3 CE) conforme a los límites que se expresan taxativamente en los mencionados preceptos señalados a modo de ejemplo, como son, «orden público» (art. 16.1 CE); conforme a «los casos y en la forma previstos en la ley» (art. 17.1 CE), «resolución judicial» y «flagrante delito» (art. 18.2 CE); «resolución judicial» (art. 18.3 CE), siempre que constituya una solución óptima. En efecto, de acuerdo a la condición de principio que la señalada cláusula restrictiva ostenta, se exige que tales intromisiones, adoptadas y practicadas conforme a tales límites sobre el correspondiente ámbito de protección, ámbito de la libertad ideológica o religiosa (art. 16.1 CE), o de la libertad personal (art. 17.1 CE), ámbito domiciliario (art. 18.2 CE), de la libertad de comunicación (art. 18.3 CE) resulten conformes al principio de proporcionalidad.

Así, pues, el acoplamiento del carácter de regla y principio que reviste cada una de las normas contenidas en la disposiciones constitucionales anteriormente transcritas y, en consecuencia, de los mandatos de prohibición y de optimización que se derivan respectivamente de ellos, implica la aplicación del principio de proporcionalidad a todos aquellos supuestos, en principio, prohibidos, por el correspondiente derecho fundamental. Cumplidos ambos requisitos, tales actuaciones estatales constituyen medidas conformes con la Constitución y, por tanto, calificables como restricciones del correspondiente derecho fundamental. Y en tal medida, cabe afirmar que se proclaman implícitamente en los preceptos constitucionales donde se contemplan. 


\section{CONCLUSIONES}

I. La construcción jurídico-dogmática de la «restricción de los Derechos Fundamentales» constituye un instrumento jurídico destinado al logro de la eficaz salvaguarda de los derechos fundamentales frente a las violaciones ocasionadas por los poderes públicos.

II. Dada la carencia de una noción de «restricción de los Derechos Fundamentales» suficientemente elaborada por nuestra doctrina, en este trabajo se ha abordado el análisis de dicho concepto. Tal noción se encuentra en evolución, debido a que ha de comprender, no sólo las vulneraciones que los poderes públicos ocasionan por una "actuación», sino también las originadas por una «omisión» en su deber de garantizarlos. Junto con dicho concepto, se ha estudiado el fundamento constitucional de este instrumento jurídico.

III. En relación con el concepto de «restricción de los Derechos Fundamentales», se ha formulado el siguiente: las restricciones o medidas restrictivas de los derechos fundamentales constituyen aquellas intromisiones que en principio vulneran el ámbito de protección de dichos derechos, lo que implica que conforman el supuesto de hecho del derecho fundamental, y que, por este motivo, precisan de justificación conforme al principio de proporcionalidad. Dicho concepto es comprensivo, tanto de las violaciones de los derechos fundamentales cometidas por una actuación de los poderes públicos (vertiente clásica de la Restricción de los Derechos Fundamentales), como de «las violaciones por omisión».

IV. De conformidad con la definición formulada, caben distinguir unos requisitos que deben cumplir los poderes públicos para que dichas injerencias sean constitucionalmente legítimas. Son: 1) las actuaciones de los poderes públicos han de constituir «intromisiones»; 2) dichas intromisiones deben caer en el «ámbito de protección» de los derechos fundamentales; y 3) tales intromisiones deben resultar respetuosas con las exigencias derivadas del «principio de proporcionalidad».

V. La inclusión de las «violaciones por omisión» en la noción de «restricción de los Derechos Fundamentales» supone la reinterpretación de los tres requisitos que la conforman. De esta manera: 1) el ámbito de protección del derecho puede resultar vulnerado, no sólo por una actuación de los poderes públicos, sino por su omisión en el deber de garantizarlo; en consecuencia, 2) las intromisiones pueden ser ocasionadas, no sólo de forma intencionada, con cobertura jurídica y con carácter inmediato, sino también de forma involuntaria, con carácter fáctico y de forma mediata; y, finalmente 3) el principio de proporcionalidad opera, cuando se trata de violaciones ocasionadas por una 
«actuación» de los poderes públicos, exigiendo la adecuación, necesidad y proporcionalidad en sentido estricto de las medidas. Y, en el caso de las violaciones "por omisión», el principio de proporcionalidad lleva a considerar principalmente al Poder Legislativo como el destinatario de tal deber de protección, sin perjuicio de que asimismo el órgano jurisdiccional tenga que aplicar el juicio de adecuación y necesidad, en el caso concreto.

VI. Junto con los tres requisitos expuestos, las medidas restrictivas han de cumplir unos presupuestos (que, aunque no se tratan específicamente en este trabajo, los analicé en profundidad, presupuestos y requisitos, en otro artículo, citado en la nota a pie de página $\mathrm{n}^{\circ} 3$ ). Son: $\mathrm{A}$ ) las medidas restrictivas han de estar legalmente previstas (a su vez, dicha regulación ha de ser respetuosa con los requisitos que conforman la noción de restricción de los derechos fundamentales); y B) han de orientarse al cumplimiento de unos «fines constitucionalmente legítimos». Ambos presupuestos fueron analizados detalladamente en otro artículo.

VII. En relación con el fundamento constitucional de la «restricción de los Derechos Fundamentales», si se parte de la "teoría externa» y se toma en consideración la Teoría de Alexy sobre el «doble carácter de las Normas de Derecho Fundamental», como reglas y principios, cabe afirmar que el instrumento jurídico de la "restricción de los Derechos Fundamentales» se encuentra implícitamente consagrado en cada una de las normas constitucionales donde se proclaman los derechos fundamentales y sus límites.

VIII. La «restricción de los Derechos Fundamentales» constituye un instrumento necesario para el Derecho Procesal porque la eficacia procesal del conjunto de medidas restrictivas que se acuerdan y practican en el marco de un proceso está supeditada al cumplimiento de los presupuestos y requisitos que las conforman. Dado que las medidas restrictivas de los derechos fundamentales pueden acordarse en distintos órdenes jurisdiccionales, ello significa que los indicados presupuestos y requisitos han de cumplirse cuando se adopten en el proceso penal, civil y contencioso-administrativo, así como en la vía administrativa previa, e, incluso, cuando, como acontece en el ámbito del proceso penal, dichas medidas restrictivas se acuerdan con el fin de luchar contra la criminalidad organizada y el terrorismo.

IX. La aplicación del concepto de restricción de los derechos fundamentales y, en concreto, de sus presupuestos y requisitos, sobre las distintas medidas procesales restrictivas de derechos fundamentales, podría utilizarse como un método de trabajo para analizar, desde una perspectiva constitucional, las medidas restrictivas que se acuerdan en el marco de un proceso. Este método ya se ha demostrado útil cuando fue aplicado en el trabajo sobre la entrada y registro 
en un domicilio (citado en la nota a pie de página $\mathrm{n}^{\circ} 3$ ). Asimismo, resulta de aplicación a todas aquellas actuaciones restrictivas de derechos fundamentales, tales como, entre otras, la intervención de las comunicaciones telefónicas o las novedosas medidas relativas a la intervención y acceso de los datos de tráfico de las comunicaciones electrónicas, así como a la obtención y tratamiento del ADN. De conformidad con el método propuesto, se comenzaría por analizar, en primer lugar, 1) sus presupuestos, esto es, A) que se encuentre legalmente prevista, lo que conlleva asimismo que dicha regulación cumpla con las exigencias propias de las medidas restrictivas y B) que persiga fines constitucionalmente previstos; $y$, en segundo término, 2) sus requisitos, lo que obliga a delimitar A) el ámbito de aplicación del derecho o derechos fundamentales que se ven vulnerados, B) los diferentes supuestos de intromisión que dicho ámbito de aplicación en principio prohíbe, (lo que, junto con el ámbito de protección conformaría el supuesto de hecho del correspondiente derecho o derechos fundamentales), y, finalmente, $\mathrm{C}$ ) los requisitos conformadores del principio de proporcionalidad que resultan aplicables a dicha medida restrictiva.

Title

THE RESTRICTION OF FUNDAMENTAL RIGHTS: A CONCEPT IN DEVELOPMENT AND ITS CONSTITUTIONAL BASIS.

\section{Summary}

1. CONCEPT. 1. The problematic of its formulation. A) The formulation of the concept in Spain and the incorporation of its equivalent in the German legal system. B) The development of «Grundrechtseingriff" and its impact in Spain. a) New forms of violation caused by the failed duty of state protection. a') Cause of duty: the objective dimension of the Fundamental Rights. b') New cases of the violations. a ") between the State and the individual citizens: unintentional and factual violations and the omissions from the Executive. b") between individual citizens who have not a legal relationship. c") between individual citizens who hava a relationship. b) The crisis of the classical concept of "Grundrechtseingriff». 2. Te new concept of the «Restricted of Fundamental Rights. A) Concept. B) Requeriments. II. CONSTITUTIONAL BASIS. 1. The theory of the «double structure of the Norms of Fundamental Right» by Alexy and the jurisprudence of the Spanish Constitutional Court. 2. The implicit declaration in each of the "Norm of Funamental Right». III. CONCLUSIONS. 


\begin{abstract}
Resumen
El concepto de «restricción de los Derechos Fundamentales» presenta una extraordinaria utilidad para el campo del Derecho Procesal. Esta circunstancia se pone de relieve a la hora de precisar las exigencias constitucionales que han de cumplir aquellos actos procesales que inciden sobre derechos fundamentales para alcanzar la eficacia procesal que persiguen. Es el caso, por ejemplo, de la entrada y registro domiciliario, la intervención de las comunicaciones telefónicas o las novedosas medidas relativas a la intervención y acceso de los datos de tráfico de las comunicaciones electrónicas, así como a la obtención y tratamiento del $\mathrm{ADN}$ e, incluso, de las medidas que cabe adoptar para luchar contra la criminalidad organizada, como la infiltración de un agente encubierto o la instalación de aparatos de escucha sobre un domicilio, cuya adopción, todos ellos, por parte del órgano jurisdiccional competente, está orientada a la PROPORCIONADA consecución de los fines propios del proceso penal, civil, así como del procedimiento administrativo. Por el hecho de incidir sobre derechos fundamentales, dichas actuaciones procesales deberían constituir restricciones o limitaciones de tales derechos, lo que significa que su eficacia procesal ha de estar sometida al más estricto cumplimiento de las exigencias constitucionales que dicha calificación conlleva. Por ello, ha de formularse el concepto de «restricción de los Derechos Fundamentales", con el objeto de precisar los presupuestos y requisitos que lo conforman. Este es precisamente el objeto de este trabajo, la exposición, en la medida en que resulta necesaria desde esta perspectiva procesal, del concepto, en evolución, de «restricción de los Derechos Fundamentales», así como su fundamento constitucional.
\end{abstract}

\begin{abstract}
The concept of «restriction of Fundamental Rights» presents an extraordinary usefulness for the field of Procedural Law. This notion comprises the constitutional requirements which have to be fulfilled by those procedural measures affecting fundamental rights. These coercive investigative measures are, for example, the entry and search of a domicile, the interception of telephone communications or the innovative measures for the intervention and access to traffic data of electronic communications, as well as DNA personal data processing and, even, some measures to fight againts organized crime, such as the infiltration of an undercover agent or the installation of listening devices in a domicile. All of these procedural measures must be taken by a competent judicial authority and must be proportionate to the aims pursued in the criminal, civil and administrative proceedings. Due to
\end{abstract}


the above procedural measures affecting fundamental right have to be qualified as restriction of Fundamental Rights which means that they are to be operated to conform with the constitutional requirements includes in this notion. Therefore, is necessary to analyze the concept or the restriction of Fundamental Rights and, in particularly, its budgets and requirements. So the aim of this paper is to expose of the above concept, which is in development, as well as its constitutional basis, from a procedural standpoint.

\section{Key Words}

Restriction of Fundamental Rights, Procedural Law, procedural measures, proportionality.

\section{Palabras clave}

Restricción de los Derechos Fundamentales, Derecho Procesal, medidas procesales, proporcionalidad. 